\title{
Alterations in Sphingolipid Composition and Mitochondrial Complex I Deficiency Represent Synergistic Therapeutic Vulnerabilities Linked to Vincristine Resistance
}

Kelsey H. Fisher-Wellman ( $\nabla$ fisherwellmank17@ecu.edu )

East Carolina University Brody School of Medicine https://orcid.org/0000-0002-0300-829X James T Hagen

East Carolina University

Miki Kassai

East Carolina University

Li-Pin Kao

East Carolina University

Margaret Nelson

East Carolina University

Kelsey McLaughlin

East Carolina University

Hannah Coalson

East Carolina University

Todd Fox

University of Virginia

Su-Fern Tan

University of Virginia

David Feith

University of Virginia

Mark Kester

University of Virginia

Thomas Loughran

University of Virginia

David Claxton

Penn State Cancer Institute

Myles Cabot

East Carolina University 
Research

Keywords: acute myeloid leukemia, sphingolipids, vincristine, chemotherapy resistance, mitochondrial bioenergetics, HL-60 cells

Posted Date: May 12th, 2021

DOl: https://doi.org/10.21203/rs.3.rs-506642/v1

License: (c) (i) This work is licensed under a Creative Commons Attribution 4.0 International License.

Read Full License 
Alterations in sphingolipid composition and mitochondrial complex I deficiency represent synergistic therapeutic vulnerabilities linked to vincristine resistance

Kelsey H. Fisher-Wellman ${ }^{5+}$, James T. Hagen ${ }^{5}$, Miki Kassai ${ }^{1}$, Li-Pin Kao ${ }^{1^{*}}$, Margaret A.M. Nelson ${ }^{5}$, Kelsey L. McLaughlin ${ }^{5}$, Hannah S. Coalson ${ }^{5}$, Todd E. Fox², Su-Fern Tan ${ }^{3}$, David J. Feith ${ }^{3,4}$, Mark Kester ${ }^{4}$, Thomas P. Loughran $\mathrm{Jr}^{3,4}$, David F. Claxton ${ }^{6}$, and Myles C. Cabot ${ }^{1+}$

${ }^{1}$ Department of Biochemistry \& Molecular Biology, East Carolina University, Brody School of Medicine, and the East Carolina Diabetes and Obesity Institute, Greenville, NC 27834, USA; 2 Department of Pharmacology, University of Virginia School of Medicine, Charlottesville, VA, USA; ${ }^{3}$ Department of Medicine, Hematology/Oncology, University of Virginia School of Medicine, Charlottesville, VA 22908, USA; “University of Virginia Cancer Center, Charlottesville, VA 22908, USA; ${ }^{5}$ Department of Physiology, East Carolina University, Brody School of Medicine, and the East Carolina Diabetes and Obesity Institute, Greenville, NC 27834, USA; 6 Penn State Cancer Institute, Hershey, Pennsylvania.

+To whom correspondence should be addressed. E-mail address: fisherwellmank17@ecu.edu, cabotm@ecu.edu

Keywords (6): acute myeloid leukemia, sphingolipids, vincristine, chemotherapy resistance, mitochondrial bioenergetics, HL-60 cells 


\section{Abstract}

Background: Modifications in sphingolipid (SL) metabolism and mitochondrial bioenergetics are key factors implicated in cancer cell response to chemotherapy, including chemotherapy resistance. Vinca alkaloids such as vincristine (VCR), widely used in cancer treatment, are no exception, as their beneficial actions are often supplanted by resistance. In the present work we utilized HL-60 human leukemia cells and a VCR-resistant counterpart, HL-60/VCR cells, to determine potential interplay between SL metabolism and mitochondrial bioenergetics supportive of VCR resistance.

Methods: Cellular SL alterations were assessed via a combination of enzyme immunoblot analysis and lipidomics. Mitochondrial function was evaluated in intact cells, permeabilized cells and isolated mitochondria using a comprehensive diagnostic assay system designed to directly interrogate oxidative phosphorylation (OXPHOS) kinetics. Informed by SL and bioenergetic readouts, experiments were designed to assess the therapeutic efficacy of co-targeting SL metabolism and mitochondrial flux to combat VCR resistance.

Results: Relative to wild-type cells, HL-60/VCR presented with global alterations in SL composition, typified by upregulated expression of sphingosine kinase (SPHK1), which catalyzes formation of sphingosine 1-phosphate (S1P), glucosylceramide synthase (GCS), which catalyzes formation of glucosylceramides (GC), and acid ceramidase, responsible for ceramide hydrolysis. In support of these changes, VCR resistance was also characterized by increases in S1P, several molecular species of ceramide and GC, and changes in sphingomyelin (SM) molecular species. With respect to mitochondria, despite increased basal respiration in $\mathrm{HL}-$ 60/VCR cells, direct interrogation of the mitochondrial network revealed intrinsic respiratory complex insufficiency, largely localized to complex I (CI). Importantly, forced ceramide accumulation in wild-type cells phenocopied the respiratory insufficiency observed in HL-60/VCR, and co-targeting SL metabolism and Cl induced synergistic cytotoxicity in HL-60/VCR.

Conclusions: Together, these data underscore the intimate connection between cellular sphingolipids and mitochondrial metabolism and suggest that pharmacological intervention across both pathways may represent a novel treatment strategy against VCR resistance. 


\section{Background}

Chemotherapy resistance is a major element underlying treatment failure in cancer. Factors contributing to resistance include drug efflux driven by multidrug resistance (MDR) membrane transport proteins (e.g.,Pglycoprotein; P-gp), drug activation/inactivation missteps, DNA damage repair, cell death inhibition (i.e., resistance to apoptosis), mutation of the target to reduce inhibitor binding, and alterations in mitochondrial bioenergetics [1-3]. These current research paradigms by and large drive the study of drug resistance in cancer. Vinca alkaloids, such as vincristine (VCR) and vinblastine (VBL), part of the World Health Organization's List of Essential Medicines, are no exception; their benefits are supplanted by upregulated expression of MDR proteins, dysfunctional apoptosis, and alterations in $\beta$-tubulin that thwart Vinca-associated microtubule targeting benefits. Despite these limitations, Vinca alkaloids are used widely in treatment of both liquid and solid tumors, and VCR as well as VBL are frequent agents in combination regimens. VCR, the focus of the present study, is a component in CVP (cyclophosphamide, VCR, prednisone) used in follicular B-cell lymphoma, CHOP (cyclophosphamide, doxorubicin, VCR, prednisone) used in large B-cell lymphoma, and was recently demonstrated to exert antileukemic effects in CD44+ AML when administered as A6 peptide functionalized polymersomal vincristine sulfate [4].

In addition to the hallmark factors underlying chemotherapy resistance, the interplay of SL's and mitochondrial bioenergetics merits consideration. Many anticancer agents raise intracellular levels of ceramides, SL's that exhibit strong tumor-suppressing activities [5]. With respect to VCR, Olshefski and Ladisch [6] have shown that VCR exposure increases ceramide levels in leukemia cells, resulting in apoptotic responses that were intensified by blocking ceramide glycosylation. Interestingly, inhibitors of SL enzymes were recently found to interfere with energy transduction across the AML mitochondrial network, suggestive of a direct link between SL metabolism and mitochondrial bioenergetics [7]. Together, these findings raise the intriguing possibility that SL-mitochondria crosstalk may play a fundamental role in chemotherapy response and thus represent an opportunity for novel therapeutic interventions against drug resistance.

Herein, we utilized VCR-resistant human leukemia cells (HL-60/VCR) to comprehensively evaluate the interplay between SL metabolism and mitochondrial bioenergetics and explore the therapeutic potential of cotargeting these pathways in drug resistance. In HL-60/VCR cells as opposed to wild-type (wt) HL-60 cells, we detail striking alterations in SL composition, highlighted by specific increases in S1P, ceramides, as well GC, and changes in levels of specific SM molecular species. These changes were accompanied by intrinsic mitochondrial remodeling that allowed for maintenance of cellular respiratory kinetics, despite intrinsic limitations in respiratory $\mathrm{Cl}$. Interestingly, despite minimal cytotoxicity as single agents, the combination of various inhibitors of SL metabolism with $\mathrm{Cl}$ inhibition induced synergistic cell death in HL-60/VCR.

\section{Methods}

Materials 
C6-ceramide (N-hexanoyl-D-erythro-sphingosine) was from Avanti Polar Lipids, Alabaster, AL. Ceramide nanoliposomes (CNL) were a generous gift from Keystone Nano, Inc. Control (ghost) formulations included all liposomal ingredients except C6- ceramide. Propidium iodide (PI) was obtained from Life Technologies/Thermo Fisher, Carlsbad, CA. SK1-i, a SPHK1 inhibitor, was from Enzo, Farmingdale, NY. Vincristine sulfate was purchased from LC Laboratories, Woburn, MA. All chemicals for mitochondrial analysis were purchased from Sigma.

\section{Cell culture}

The human, VCR resistant (multidrug resistant) cell line, HL-60/VCR was provided by A.R. Safa, Indiana University School of Medicine, Indianapolis, IN. Cells were cultured in RPMI-1640 medium, (Life Science Technologies, Carlsbad, CA), supplemented with 10\% FBS (Peak Serum, Wellington, CO), 100 units/ml penicillin, and $100 \mu \mathrm{g} / \mathrm{ml}$ streptomycin (Life Science Technologies), and $1.0 \mu \mathrm{g} / \mathrm{ml}(1.2 \mu \mathrm{M}$ ) vincristine sulfate (dissolved in water). For experiments testing the impact of VCR withdrawal, HL-60/VCR cells were cultured in RPMI-1640 growth medium devoid of vincristine sulfate for 7 days. HL-60 cells were obtained from the ATCC, Manassas, VA. This cell line was not tested and authenticated over, and above documentation provided by the ATCC, which includes antigen expression, DNA profile, short tandem repeat profiling, and cytogenic analysis.

Cell viability assays

Cell viability was determined by fluorescence measurement as previously described [8]. Briefly, cells were seeded in Corning black wall, 96-well plates (VWR, Suwanee, GA), treated with indicated agents in a final volume of $0.2 \mathrm{ml}$ RPMI-1640 complete medium, and incubated at $37^{\circ} \mathrm{C}, 5 \% \mathrm{CO}_{2}$, for the times indicated. Viability was determined using $\mathrm{PI}$ as follows. Cells (positive controls corresponding to $100 \%$ cell death) were permeabilized by addition of $10 \mu \mathrm{l}$ of $1 \mathrm{mg} / \mathrm{ml}$ digitonin and incubated at $37^{\circ} \mathrm{C}, 5 \% \mathrm{CO}_{2}$ for 20 min, followed by addition of PI dissolved in PBS, at a final concentration of $5 \mu \mathrm{M}$. The plate was incubated for 20 minutes, and viability was calculated as the mean $(n=6)$ fluorescence (minus non-permeabilized control) at $530 \mathrm{~nm}$ excitation and $620 \mathrm{~nm}$ emission, using a BIO-TEK Synergy H1 microplate reader (Winooski, VT). Viability was also determined using trypan blue $(0.4 \%)$ exclusion and cell counting on a Countess II apparatus, Life Science Technologies, using disposable hemocytometers, from Invitrogen, Thermo/Fisher Scientific; cell growth rates were assessed by the same method.

\section{Lipidomics}

Lipidomic analysis was conducted using liquid chromatography-electrospray ionization-tandem mass spectrometry (LC-ESI-MS/MS) as previously described [8]. Briefly, total lipids were extracted from cells after addition of internal standards using ethyl acetate/isopropanol/water (60:30:10, v/v) without phase partitioning. Separation of lipid extracts was achieved using a Waters I-class Acquity LC with a $2.1 \times 100 \mathrm{~mm} \mathrm{C18} \mathrm{CSH} \mathrm{column}$ and detected with a Waters Xevo TQ-S MS system. 
Immunoblotting was conducted as previously described $[9,10]$ with modifications. SPHK1 (47 kDa, catalog \# 12071), used at 1:1000 dilution, and $\beta$-actin (45 kDa, catalog \# 3700), used at 1:3000 dilution, were from Cell Signaling. P-gp (180 kDa, catalog \# NB60D-1036), used at 1:1000 dilution, was from Novus (Imgenex). GCS (40 kDa, catalog \# PA5-42111), used at a 1:1000 dilution, was from Invitrogen. AC (13 kDa, catalog \# 612302), used at a 1:1000 dilution, was from Labome (BD Bioscience). Briefly, cells were lysed in 1x RIPA buffer (Cell Signaling Technology, Danvers, MA, USA) containing phosphatase inhibitor cocktail 2, protease inhibitor, and PMSF (1.0 mM), according to the manufacturer's protocol (Sigma Chemical Company). The bicinchoninic acid (BCA) method was employed for determining protein concentrations. Lysates were centrifuged to remove debris and then heated in 1x NuPage LDS sample buffer at $95^{\circ} \mathrm{C}$ for 5 min (GCS lysate was heated at $55^{\circ} \mathrm{C}$ for $5 \mathrm{~min}$ ). Equal amounts of total protein were separated by SDS-polyacrylamide gel electrophoresis and subsequently transferred onto PVDF or nitrocellulose membranes (Millipore, Billerica, MA, USA). The membranes were blocked with $5 \%$ non-fat milk in PBS for $1 \mathrm{hr}$ at room temperature and incubated with primary antibodies according to the manufacturer's instructions, at $4^{\circ} \mathrm{C}$ overnight. The membranes were washed with PBST, followed by incubation with the corresponding HRP-conjugated secondary antibodies according to the manufacturer's instructions, for $1 \mathrm{hr}$ at room temperature. The membranes were washed with PBST before exposure. Bound antibodies were measured using an enhanced chemiluminescence detection kit (Thermo Fisher Scientific) and surveyed using a ChemiDoc imaging system (Bio-Rad, Hercules, CA). The relative intensity of protein expression was calculated using ImageJ software (National Institutes of Health).

\section{Quantitative reverse transcription PCR (RT-PCR)}

An RNA extraction kit (Qiagen Pty., Ltd, Waltham, MA) was used to extract total RNA, which was then reverse-transcribed into cDNA using a ProtoScript II First Strand cDNA Synthesis Kit (New England Biolabs, Ipswich, MA). The synthesized cDNAs were amplified with SYBR Premix (Bimake, Houston, TX) using the ABI VII7 Real-Time PCR System (Invitrogen). The PCR cycling parameters were $50^{\circ} \mathrm{C}$ for 2 min and $95^{\circ} \mathrm{C}$ for $10 \mathrm{~min}$, followed by 40 cycles of $95^{\circ} \mathrm{C}$ for $15 \mathrm{~s}$ and $60^{\circ} \mathrm{C}$ for $1 \mathrm{~min}$. Relative mRNA levels were calculated using the comparative $\mathrm{Ct}$ method (Applied Biosystems instruction manual) and presented as ratios to their biological controls. The fold change in expression of each target mRNA relative to $\beta$-actin was calculated as $2^{\Delta(\Delta C t)}$, where $\Delta \mathrm{Ct}=\Delta \mathrm{Ct}_{\beta \text {-acin }}-\mathrm{Ct}_{\text {genes. }} \beta$-actin transcript levels were confirmed to correlate well with total RNA levels and therefore were used for normalization throughout the experiments [11,12]. The primers used for real-time PCR were designed by primerbank (http://pga.mgh.harvard.edu/primerbank/): (ABCB1: F:TTGCTGCTTACATTCAGGTTTCA, R:AGCCTATCTCCTGTCGCATTA; $\quad$ ABCC1: F: CTCTATCTCTCCCGACATGACC, R: AGCAGACGATCCACAGCAAAA; ABCG2: F: ACGAACGGATTAACAGGGTCA, R: CTCCAGACACACCACGGAT; $\beta$-actin: F:GCTGTGCTACGTCGCCCTG, R:GGAGGAGCTGGAAGCAGCC).

Cellular respirometry (intact and permeabilized) 
High-resolution $\mathrm{O}_{2}$ consumption measurements were conducted using the Oroboros Oxygraph-2K (Oroboros Instruments, Innsbruck, Austria) in intact and digitonin permeabilized HL-60 and HL-60/VCR cells. For each intact cell experiment, cells were centrifuged at 1,000 rpm for $7 \mathrm{~min}$ at room-temperature, washed in PBS, centrifuged once more and then suspended in assay media at a cell concentration of 2-3 $310^{6}$ viable cells/ml. Assay media was RPMI 1640, without bicarbonate, supplemented with $20 \mathrm{mM} \mathrm{HEPES} \mathrm{(pH} \mathrm{7.4),} \mathrm{10 \%}$ FBS, 100 units $/ \mathrm{ml}$ penicillin, and $100 \mu \mathrm{g} / \mathrm{ml}$ streptomycin. All experiments were carried out at $37^{\circ} \mathrm{C}$ in a $1-\mathrm{mL}$ reaction volume. Following the assessment of basal respiration, the following sequential additions were made (oligomycin $(5.0 \mu \mathrm{M}), \mathrm{FCCP}(0.5,1,2,3 \mu \mathrm{M})$, rotenone (Rot; $5 \mu \mathrm{M})$, antimycin A (Ant A; $5 \mu \mathrm{M}$ ). For experiments designed to assess the impact of P-gp, verapamil $(10 \mu \mathrm{M})$ was added prior to oligomycin to intact cells. For permeabilized cell experiments, cells were centrifuged at 1,000 rpm for $7 \mathrm{~min}$ at room-temperature, washed in respiration buffer, centrifuged once more and then suspended in respiration buffer at a cell concentration of 2-3 x $10^{6}$ viable cells/mL. Respiration buffer consisted of potassium-MES (105 mM; pH 7.2), $\mathrm{KCl}(30 \mathrm{mM}), \mathrm{KH}_{2} \mathrm{PO}_{4}$ (10 mM), $\mathrm{MgCl}_{2}(5 \mathrm{mM})$, EGTA $(1 \mathrm{mM})$, and BSA (2.5 g/L). After recording basal respiration, cells were permeabilized with digitonin $(20 \mu \mathrm{g} / \mathrm{mL})$, energized with saturating carbon (pyruvate/malate/glutamate/succinate/octanoyl-I-carnitine; P/M/G/S/O; $5 \mathrm{mM} / 2 \mathrm{mM} / 5 \mathrm{mM} / 5 \mathrm{mM} / 0.2 \mathrm{mM}$ ) and flux was stimulated with FCCP titration $(0.5-3.0 \mu \mathrm{M})$. Cytochrome $\mathrm{C}(10 \mu \mathrm{M})$ was added to check the integrity of the outer mitochondrial membrane and then respiration was inhibited with rotenone (Rot; $5 \mu \mathrm{M})$ and antimycin $\mathrm{A}$ (Ant $\mathrm{A} ; 5 \mu \mathrm{M}$ ). Data were normalized to viable cell count and expressed as $\mathrm{pmol} / \mathrm{s} / \mathrm{million}$ cells.

\section{Mitochondrial isolation}

As described previously [13] and with some modifications, cells were centrifuged at $300 \times \mathrm{g}$ for $10 \mathrm{~min}$ followed by a PBS wash. Cell pellets were resuspended in Mitochondrial Isolation Buffer with BSA (100mM KCl, $50 \mathrm{mM}$ MOPS, $1 \mathrm{mM}$ EGTA, $5 \mathrm{mM} \mathrm{MgSO}_{4}, 0.2 \%$ BSA, pH 7.1) and homogenized using a borosilicate glass mortar and Teflon pestle. Homogenates were centrifuged at $800 \times \mathrm{g}$ for $10 \mathrm{~min}$ at $4^{\circ} \mathrm{C}$. The supernatant was collected, and this process was repeated for a total of 3 times. The collected supernatant was centrifuged at $10,000 \times \mathrm{g}$ for $10 \mathrm{~min}$ at $4^{\circ} \mathrm{C}$ to pellet the mitochondrial fraction. The fraction was resuspended in Mitochondrial Isolation Buffer without BSA, transferred to a microcentrifuge tube and spun down at 10,000 $\mathrm{xg}$. Final resuspension of the mitochondrial pellet was done in Mitochondria Isolation Buffer and protein concentration was calculated using the Pierce BCA assay. Respiration assays using isolated mitochondria were similar to that described for permeabilized cells.

\section{Mitochondrial functional assessment (isolated mitochondria)}

High-resolution $\mathrm{O}_{2}$ consumption rate $\left(\mathrm{JO}_{2}\right)$ measurements were conducted using the Oroboros Oxygraph-2K (Oroboros Instruments, Innsbruck, Austria). The base assay buffer was identical to that used in permeabilized cells (105mM potassium-MES, $30 \mathrm{mM} \mathrm{KCl}, 10 \mathrm{mM} \mathrm{KH}_{2} \mathrm{PO}_{4}, 5 \mathrm{mM} \mathrm{MgCl}_{2}, 1 \mathrm{mM}$ EGTA, 2.5g/L BSA and $5 \mathrm{mM}$ creatine monohydrate; $\mathrm{pH}=7.2)$. As previously described [13,14], a modified version of the $\mathrm{CK}$ clamp technique was used to determine steady-state $\mathrm{JO}_{2}$ across a physiological $\Delta \mathrm{G}_{\mathrm{ATP}}$ span. For complete details 
regarding the calculation of $\Delta G_{A T P}$ at each titration point see [14]. To begin, mitochondria were added to respiration buffer, followed by the addition of respiratory substrates to stimulate State 4 (i.e., nonphosphorylating) respiration. The CK clamp was then initiated by the addition of ATP (5mM), PCr (1mM), and CK (20U/ml), simulating a 'maximal' demand for ATP re-synthesis. Sequential additions of PCr to 6, 15, and $21 \mathrm{mM}$ were then performed to gradually lower the ATP demand state and assess OXPHOS conductance. Four substrate conditions were used: Pyr/M (5mM/1mM); glutamate/M (G/M; 10mM/1mM); S/Rot (10mM/0.5 $\mu \mathrm{M})$; $\mathrm{P} / \mathrm{M} / \mathrm{G} / \mathrm{S} / \mathrm{O}$ (5mM/1mM/5mM/5mM/0.2mM; Multi). For experiments involving dihydroorotate (DHO), DHO (2mM) was added to isolated mitochondria in the presence of saturating ADP (2mM). DHO-supported respiration was then inhibited using a specific inhibitor of dihydroorotate dehydrogenase (DHODH), teriflunomide (20 $\mu M)$. Data were normalized to protein loaded per experiment and then corrected for the mitochondrial enrichment factor $\left({ }^{*}\right)$ calculated for that sample, with the final values expressed as $\mathrm{pmol} / \mathrm{s} / \mathrm{mg}$ protein* (see proteomics methodology below).

\section{Mitochondrial NADH/NAD+ redox in isolated mitochondria}

Fluorescent determination of $\mathrm{NADH} / \mathrm{NAD}^{+}$was performed using a QuantaMaster Spectrofluorometer (QM-400, Horiba Scientific, Kyoto, Japan). The NADH/NAD+ was detected at Ex/Em: 350/450. NADH/NAD+ was measured in mitochondria using the CK clamp assay. Experiments were performed at $37^{\circ} \mathrm{C}$ in a $200 \mu \mathrm{L}$ reaction volume. Mitochondria were incubated at $37^{\circ} \mathrm{C}$ for $\sim 5$ minutes without substrate to induce $0 \%$ reduction of the NADH pool. Saturating carbon substrates were added (Multi), and respiration was stimulated with the CK clamp. Titration of $\Delta \mathrm{G}_{\mathrm{ATP}}$ was performed via PCr titration $(6,15,21 \mathrm{mM})$. Oligomycin $(0.02 \mu \mathrm{M})$ was added to inhibit ATP synthesis and cyanide (CN, 10mM) was added to induce $100 \%$ reduction of the matrix NADH pool. The NADH/NAD+ was expressed as a percentage reduction of the $\mathrm{CN}$ value (i.e. $100 \%$ reduction) based upon the formula $\%$ Reduction $=\left(F-F_{0 \%}\right) /\left(F_{100 \%}-F_{0 \%}\right)^{*} 100$.

Mitochondrial $\mathrm{H}_{2} \mathrm{O}_{2}$ emission

Mitochondrial peroxide emission was assessed in Respiration buffer, supplemented with amplex ultra red $(5 \mu \mathrm{M})$, horse radish peroxidase (HRP; $1 \mathrm{U} / \mathrm{mL})$, and superoxide dismutase $(25 \mathrm{U} / \mathrm{mL})$, as described previously [15]. Experiments were run in the presence of mitochondria alone, Pyr/M $(5 \mathrm{mM} / 2 \mathrm{mM})$, and the CK clamp. Relative fluorescence was converted to pmol of $\mathrm{H}_{2} \mathrm{O}_{2}$ using an $\mathrm{H}_{2} \mathrm{O}_{2}$ standard curve, as previously described [15].

Mitochondrial lysis and sample prep for label-free proteomics

Isolated mitochondria were lysed in urea lysis buffer ( $8 \mathrm{M}$ urea in $40 \mathrm{mM}$ Tris, $30 \mathrm{mM} \mathrm{NaCl}, 1 \mathrm{mM} \mathrm{CaCl}_{2}, 1$ x cOmplete ULTRA mini EDTA-free protease inhibitor tablet; $\mathrm{pH}=8.0$ ), as described previously [13,16]. The samples were subjected to three freeze-thaw cycles, and sonication with a probe sonicator in three $5 \mathrm{~s}$ bursts $(Q$ Sonica \#CL-188; amplitude of 30 ). Samples were centrifuged at $10,000 \times \mathrm{g}$ for $10 \mathrm{~min}$ at $4^{\circ} \mathrm{C}$. Protein concentration was determined by BCA. Equal amounts of protein were reduced with $5 \mathrm{mM} \mathrm{DTT}$ at $37^{\circ} \mathrm{C}$ for $30 \mathrm{~min}$, 
and then alkylated with $15 \mathrm{mM}$ iodoacetamide for $30 \mathrm{~min}$ in the dark at room temperature. Unreacted iodoacetamide was quenched with DTT $(15 \mathrm{~mm})$. Initial digestion was performed with Lys C (ThermoFisher Cat\# $90307 ; 1: 100 \mathrm{w}: \mathrm{w})$ for $4 \mathrm{hr}$ at $37^{\circ} \mathrm{C}$. Following dilution to $1.5 \mathrm{M}$ urea with $40 \mathrm{mM}$ Tris $(\mathrm{pH}=8.0), 30 \mathrm{mM} \mathrm{NaCl}, 1 \mathrm{mM}$ $\mathrm{CaCl}_{2}$, samples were digested overnight with trypsin (Promega; Cat\# V5113; 50:1 w/w) at $37^{\circ} \mathrm{C}$. Samples were acidified to $0.5 \%$ TFA and then centrifuged at $4,000 \times \mathrm{g}$ for $10 \mathrm{~min}$ at $4^{\circ} \mathrm{C}$. Supernatant containing soluble peptides was desalted, as described previously [16] and then eluate was frozen and subjected to speedvac vacuum concentration.

\section{nLC-MS/MS for label-free proteomics}

Final peptides were resuspended in $0.1 \%$ formic acid, quantified (ThermoFisher Cat\# 23275), and then diluted to a final concentration of $0.25 \mu \mathrm{g} / \mu \mathrm{L}$. Samples were subjected to nanoLC-MS/MS analysis using an UltiMate 3000 RSLCnano system (ThermoFisher) coupled to a Q Exactive Plus Hybrid Quadrupole-Orbitrap mass spectrometer (ThermoFisher) via a nanoelectrospray ionization source. For each injection, $4 \mu \mathrm{L}(1 \mu \mathrm{g})$ of sample was first trapped on an Acclaim PepMap $10020 \mathrm{~mm} \times 0.075 \mathrm{~mm}$ trapping column (ThermoFisher Cat\# $164535 ; 5 \mu \mathrm{L} / \mathrm{min}$ at $98 / 2 \mathrm{v} / \mathrm{v}$ water/acetonitrile with $0.1 \%$ formic acid). Analytical separation was performed over a $95 \mathrm{~min}$ gradient (flow rate of $250 \mathrm{~nL} / \mathrm{min}$ ) of $4-25 \%$ acetonitrile using a $2 \mu \mathrm{m}$ EASY-Spray PepMap RSLC C18 $75 \mu \mathrm{m} \times 250 \mathrm{~mm}$ column (ThermoFisher Cat\# ES802A) with a column temperature of $45^{\circ} \mathrm{C}$. MS1 was performed at 70,000 resolution, with an AGC target of $3 \times 10^{6}$ ions and a maximum injection time (IT) of 100ms. MS2 spectra were collected by data-dependent acquisition (DDA) of the top 15 most abundant precursor ions with a charge greater than 1 per MS1 scan, with dynamic exclusion enabled for 20s. Precursor ions isolation window was $1.5 \mathrm{~m} / \mathrm{z}$ and normalized collision energy was 27 . MS2 scans were performed at 17,500 resolution, maximum IT of $50 \mathrm{~ms}$, and $A G C$ target of $1 \times 10^{5}$ ions.

\section{Data analysis for label-free proteomics}

As described previously [16], with some modification, Proteome Discoverer 2.2 (PDv2.2) was used for raw data analysis, with default search parameters including oxidation (15.995 Da on $\mathrm{M}$ ) as a variable modification and carbamidomethyl (57.021 Da on C) as a fixed modification. Data were searched against the Uniprot Homo Sapiens reference proteome (Proteome ID: UP000005640), as well as the Human Mito Carta 2.0 database [17]. PSMs were filtered to a $1 \%$ FDR and grouped to unique peptides while maintaining a $1 \%$ FDR at the peptide level. Peptides were grouped to proteins using the rules of strict parsimony and proteins were filtered to $1 \%$ FDR. Peptide quantification was done using the MS1 precursor intensity. Imputation was performed via low abundance resampling. Using only high confidence master proteins, mitochondrial enrichment factor (MEF) was determined as previously described [13] by comparing mitochondrial protein abundance (i.e., proteins identified to be mitochondrial by cross-reference with the MitoCarta 2.0 database) to total protein abundance.

\section{Statistical evaluation}


All mass spectrometry samples were normalized to total protein abundance, and the protein tab in the PDv2.2 results was exported as a tab delimited .txt. file and analyzed. Protein abundance was converted to the $\log _{2}$ space. For pairwise comparisons, tissue mean, standard deviation, p-value ( $p$; two-tailed Student's t-test, assuming equal variance), and adjusted p-value (Benjamini Hochberg FDR correction) were calculated [18,19].

Mitochondrial assay results are expressed as the mean \pm SEM (error bars). Data were normalized to protein loaded per experiment and then corrected for the mitochondrial enrichment factor $\left(^{*}\right)$ calculated for that sample, or the group mean, with the final values expressed as pmol/s/mg protein*. For a detailed description of this method, see previous publication [13]. Throughout the paper, differences between groups were assessed by t-test, or one-way ANOVA, followed by Tukey's test where appropriate using GraphPad Prism 8 software (Version 8.4.2). Other statistical tests used are described in the figure legends. Statistical significance in the figures is indicated as follows: ${ }^{*} p<0.05 ;{ }^{* *} p<0.01$; ${ }^{* *} p<0.001 ;{ }^{* * *} p<0.0001$. Unless otherwise stated, figures were generated using GraphPad Prism 8 software (Version 8.4.2) or Biorender.

\section{Results}

\section{HL-60/VCR cell characteristics}

The cell line used in the present work, HL-60/VCR, was developed by Safa and colleagues from HL60/Vinc cells, originally developed by Melvin S. Center, Division of Biology, Kansas State University, Manhattan, KS, by step-wise selection to increasing concentrations of VCR [20]. To confirm the VCR resistance status in our model, we determined sensitivity to VCR in wt and in HL-60/VCR cells. As shown, HL-60/VCR cells were more resistant to VCR compared to the VCR-naïve, wt counterpart (Fig. 1A), with $I_{50}$ values of 10.6 (12.8 $\left.\mu \mathrm{M}\right)$ and $0.001 \mu \mathrm{g} / \mathrm{ml}(1.2 \mathrm{nM})$, respectively, translating to a >10,000-fold difference in sensitivity. From a morphological perspective, wt and VCR-resistant cells were similar in size and appearance; however, HL60/VCR cells tend to clump in suspension (photos not shown). Cell growth rate was however slower in drug resistant cells compared to wt, with HL-60/VCR growing at 57\% the rate of wt cells (Fig. 1B). Lastly, and as expected, ABCB1 transcription (P-glycoprotein, P-gp) was markedly elevated (2000-fold) in HL-60/VCR cells along with a slight but significant increase (3-fold) in ABCC1 (multidrug resistance protein, MRP), and (25-fold) ABCG2 (breast cancer resistant protein, BCRP) compared to wt cells (Fig. 1C).

\section{Alterations in SL enzyme expression accompany VCR resistance}

Because of the key role that SL's play in cancer growth [21,22] and response to chemotherapy [23], we were interested in assessing the impact of VCR resistance on expression of several enzymes involved in SL metabolism. Firstly, levels of total SPHK1 were elevated in HL-60/VCR cells compared to the wt counterpart (Fig. 1D-E). Regarding SPHK1, it is important to note that the product of this enzyme, S1P, is mitogenic, and thus favors neoplastic growth. GCS, which catalyzes glycosylation of ceramide to GC, and in effect dulls ceramide's tumor-suppressor activity by reducing ceramide levels, was overexpressed in VCR-resistant cells (Fig. 1D-E). This change in glycosphingolipid metabolism has been shown to accompany MDR [24]. Acid 
ceramidase (AC) expression was also enhanced in HL-60/VCR compared to wt cells (Fig. 1D-E), as previously demonstrated in HL-60/VCR cells [25]. Lastly, although expected, HL-60/VCR cells exhibited markedly elevated levels of P-gp (Fig. 1D-E).

\section{Lipidomic analysis}

Complementary with immunoblot data, HL-60/VCR cells presented with multi-fold increases in S1P and dh-S1P levels, compared to wt cells (Fig. 1F). Sphingosine levels were similar in both cell lines, whereas the levels of dihydrosphingosine (dhSph), also termed sphinganine, were diminished by approximately $75 \%$ in $\mathrm{HL}$ 60/VCR cells (Fig. 1F). The levels of several ceramide molecular species were increased in HL-60/VCR cells, including C14:0, C16:0, C24:1, as well as the C26 species, C26 and C26:1 (Fig. 1G). The increases in ceramide molecular species were mirrored by concomitant increases in corresponding GC species, as shown for example in C14:0, C16:0, C22:1, C24:1, and C26 molecular species (Fig. 1G). Several molecular species of SM were decreased in HL-60/VCR cells versus wt, as demonstrated in C18, C20, C22, and C24 (Fig. 1G). On the opposing side, C22:1 SM levels were elevated and a marked increase in C26:1 SM was clearly shown in VCRresistant cells (Fig. 1G). In summary, the data in Fig. 1 demonstrate widespread alterations in SL composition occur with VCR resistance, and interestingly, C22:1 ceramide appears to be sequestered in GC and SM.

Intact cellular respirometry in VCR resistance reveals increased mitochondrial content.

Mitochondria play a key role in cancer cell biology and are increasingly recognized as potential targets in cancer therapy [26]. Mitochondria are also important downstream targets of ceramide [27,28]. Considering the dynamic changes in SL profiles and enzyme expression patterns that accompanied VCR resistance, we sought to determine whether mitochondrial metabolism was impacted in the process. To begin, initial respirometry experiments were performed in intact cells under basal conditions, as well as in response to ATP synthase inhibition (i.e., oligomycin), chemical uncoupling (i.e., the addition of the protonophore FCCP), and electron transport inhibition (i.e., rotenone and antimycin A). Respiration under basal conditions was 2-fold higher in HL60/VCR compared to wt cells (Fig. 2A, basal abbreviated by 'Basal'). Interestingly, the ability of oligomycin to lower respiration was blunted in HL-60/VCR (Fig. 2A, 'Oligo'). Although inhibition of $\mathrm{JO}_{2}$ by oligomycin is typically interpreted to reflect OXPHOS 'coupling efficiency', we hypothesized that high P-gp expression in HL-60/VCR could be driving oligomycin efflux. To test this, oligomycin-mediated inhibition of basal respiration was assessed in HL-60/VCR cells in the presence of the P-gp inhibitor verapamil. Under these conditions, oligomycin inhibited basal respiration similar to that seen in wt cells (Fig. 2B), confirming P-gp mediated efflux of oligomycin. Maximal uncoupled respiration was nearly 2-fold higher in HL-60/VCR and respiration remained higher in HL-60/VCR following the addition of both rotenone and antimycin $A$, suggesting increased non-mitochondrial oxidase activity in HL-60/VCR (Fig. 2A, 'Rot/Ant'). Correcting for non-mitochondrial $\mathrm{JO}_{2}$, maximal uncoupled respiration was higher in HL-60/VCR (Fig. 2C), consistent with previous findings linking increased mitochondrial content to $A M L$ chemoresistance [2,29]. In our model system, HL-60/VCR were continuously cultured in the presence of $1.0 \mu \mathrm{g} / \mathrm{mL}(1.2 \mu \mathrm{M}) \mathrm{VCR}$. To determine if the bioenergetic phenotype observed in VCR resistant cells was 
attributable to maintaining our stock cultures in VCR medium, we repeated our respirometry experiments in HL60/VCR cultured in growth media devoid of VCR for seven days. Results revealed nearly identical results to that observed in cells continuously exposed to VCR (Fig. 2A, 'VCR ${ }^{+V C R}$ ' Vs 'VCR-VCR').

Comprehensive mitochondrial phenotyping in VCR resistance reveals functional limitations in $\mathrm{Cl}$

Increased basal respiration and higher mitochondrial mass are commonly observed bioenergetic phenotypes associated with drug-resistance [2,30]. Although such phenotypes are presumed to reflect an increased reliance on oxidative ATP production, how the mitochondrial network is intrinsically remodeled to support the drug resistant phenotype remains poorly understood. To begin to address this gap, we first sought to validate our intact cell respirometry data by directly measuring mitochondrial respiratory capacity in substrate replete permeabilized cells. Surprisingly, despite higher basal respiration (Fig. 2D 'Cells'), maximal respiratory capacity induced via FCCP titration was decreased, rather than increased, in HL-60/VCR cells (Fig. 2D 'FCCP'), suggesting intrinsic dysregulation across the VCR mitochondrial network. Similar results were observed in HL60/VCR cultured for seven days in VCR-free culture media (Fig. 2D). Importantly, the addition of cytochrome C did not increase respiratory flux in any group (Fig. 2D), indicating that the respiratory limitations in VCR were not attributable to outer membrane permeabilization. To probe deeper, we isolated mitochondria from wt and VCR resistant HL-60 cells and comprehensively evaluated mitochondrial bioenergetic function. Using this workflow, we can model the impact of a physiological ATP free energy (i.e, $\Delta G_{A T P}$ ) span on respiratory flux [14,31]. Experimental manipulation of $\Delta \mathrm{G}_{\mathrm{ATP}}$ is made possible via a modified version of the creatine kinase (CK) energetic clamp [32]. This technique leverages the enzymatic activity of CK, which couples the interconversion of ATP and ADP to that of phosphocreatine (PCr) and free creatine $(\mathrm{Cr})$ to titrate the extra-mitochondrial ATP/ADP ratio and allow direct interrogation of OXPHOS kinetics in the presence of various substrate/inhibitor combinations.

To begin, isolated mitochondria from wt and VCR resistant HL-60 cells, either continuously exposed to VCR in culture or following 7-day withdrawal, were energized with saturating carbon (pyruvate, malate, glutamate, octanoyl-carnitine, succinate; indicated by 'Multi') and respiration was stimulated with the CK clamp at minimal ATP free energy to mimic maximal OXPHOS demand. Subsequent titrations in PCr were then performed to gradually lower ATP resynthesis. Both maximal respiratory flux and OXPHOS conductance (i.e., the slope of the $\mathrm{JO}_{2}$ vs $\Delta \mathrm{G}_{\text {ATP }}$ relationship) were decreased in HL-60/VCR (Fig. 3A-B). To identify the source of decreased OXPHOS conductance in HL-60/VCR, NADH/NAD+ redox poise was measured in parallel in substrate-replete isolated mitochondria exposed to an identical $\triangle G_{A T P}$ span. Results revealed NADH/NAD ${ }^{+}$ hyper-reduction in HL-60/VCR mitochondria (Fig. 3C), indicating that OXPHOS impairments in HL-60/VCR are not due to a generalized impairment in dehydrogenase flux, but likely attributable to respiratory complex limitations (i.e., the electron transport system; ETS).

To investigate complex specific OXPHOS kinetics, mitochondria were energized with either a $\mathrm{Cl}(\mathrm{Pyr} / \mathrm{M})$ or CII (Succ/R) specific substrate combination and respiration was again stimulated with the CK clamp. At minimal $\Delta G_{A T P}$, respiration support by Pyr/M was nearly 2-fold lower in HL-60/VCR (Fig. 3D), despite no 
differences in the presence of S/Rot (Fig. 3E). These findings suggested that the respiratory impairments observed with Pyr/M were either caused by limitations in pyruvate uptake/metabolism or due to a generalized impairment in NADH-linked flux (i.e., Cl limitations). To distinguish between these possible phenotypes, we performed an additional respirometry assay in which $\mathrm{Cl}$-supported flux was fueled with G/M to provide NADH that circumvents pyruvate metabolism (Fig. 3F). Under these conditions, G/M supported $\mathrm{JO}_{2}$ was again reduced in HL-60/NCR (Fig. 3F), suggesting a specific bioenergetic limitation localized at Cl. In support of this, a dihydroorotate (DHO) assay was performed to provide electrons directly to the ubiquinone pool, thus bypassing $\mathrm{Cl}$ in a manner comparable to succinate. Respiration supported by DHO was higher in HL-60/VCR (Fig. 3G), further corroborating a Cl-specific limitation in HL-60/VCR. Interestingly, even in the absence of carbon substrate, mitochondrial respiration was elevated in HL-60/VCR, suggesting the involvement of increased mitochondrial oxidase activity (Fig 3G, 'ADP'). To address this, we assessed mitochondrial $\mathrm{H}_{2} \mathrm{O}_{2}$ emission in deenergized mitochondria, as well as in response to Pyr/M and the CK clamp (Fig. 3H-I). Results revealed an over 10-fold increase in $\mathrm{H}_{2} \mathrm{O}_{2}$ emission in $\mathrm{HL}-60$ /VCR under all conditions (Fig. $\mathbf{3 H}-\mathbf{I}$ ). Interestingly, while the addition of the $\mathrm{CK}$ clamp decreased peroxide emission in wt mitochondria, presumably as a result of decreased redox pressure, $\mathrm{H}_{2} \mathrm{O}_{2}$ emission was unaffected by ATP free energy in $\mathrm{HL}-60 /$ CR (Fig. 3H-I). Such results are consistent with elevated $\mathrm{NAD}(\mathrm{P}) \mathrm{H}$ oxidase activity in $\mathrm{HL}-60 / \mathrm{V} \mathrm{R}$ mitochondria and provide a potential explanation for the increased rotenone/antimycin insensitive respiration observed in intact cells (Fig. 2A).

To identify the mechanism of $\mathrm{Cl}$ deficiency in HL-60/VCR, we conducted a label-free quantitative proteomics screen using peptides prepared from the same isolated mitochondria samples used for functional characterization. In total we identified 385 differentially expressed mitochondrial proteins (adjusted $\mathrm{P}$ value $<$ 0.01) comparing wt to HL-60/VCR (Supplementary Table 1). Focusing in on the respiratory complexes exclusively, the vast majority of $\mathrm{Cl}$ subunits were specifically downregulated in HL-60/VCR (Fig. 4A). Interestingly, the core subunits of succinate dehydrogenase (i.e., CII) were increased in HL-60/VCR, presumably to compensate for $\mathrm{Cl}$ partial loss-of-function (Fig. 4A). To explore the biological consequences of $\mathrm{Cl}$ deficiency in HL-60/VCR, we assessed cell viability in the absence and presence of increasing concentrations of the $\mathrm{Cl}$ inhibitor, rotenone (Fig. 4B-C). Consistent with partial Cl loss-of-function, HL-60/VCR cells were found to be highly sensitized to rotenone-induced cytotoxicity (Fig $3 \mathrm{C}$ ). Taken together, these findings reveal $\mathrm{Cl}$ deficiency as a previously unidentified bioenergetic vulnerability that accompanies VCR resistance.

Forced ceramide accumulation in wt cells phenocopies respiratory complex insufficiency observed with VCR resistance.

Pharmacological inhibition of AC, sufficient to increase cellular ceramide molecular species, was recently demonstrated to decrease mitochondrial respiratory competence in drug resistant AML [7]. Interestingly, respiratory limitations were independent of both carbon substrate and respiratory stimulus and were observed despite no evidence of mitochondrial outer membrane permeabilization. Such findings suggested the intriguing possibility that cellular ceramides may be capable of directly regulating mitochondrial ETS function. In the present 
study, VCR resistance was associated with substantial increases in a variety of ceramide molecular species (Fig. 1G). Based on this, we hypothesized that $\mathrm{Cl}$ deficiency may be consequential to ceramide accumulation in HL-60/VCR. To determine whether elevated ceramide levels seen in HL-60/VCR cells infringe on mitochondrial function, we grew HL-60 wild-type cells for extended periods (7-days) in medium containing either C6-ceramide $(\mathrm{C} 6 ; 10 \mu \mathrm{M})$ or ceramide delivered via nanoliposome $(\mathrm{CNL} ; 10 \mu \mathrm{M})$, both sources for the production of long-chain ceramides [33,34]. Following 7-days of exposure, mitochondrial OXPHOS kinetics in permeabilized cells was assessed. Despite no change respiration in the presence of Pyr/M in the absence of adenylate stimulation (Fig. 5A; 'Pyr/M'), stimulation of near-maximal OXPHOS flux with the CK clamp revealed a nearly 2-fold decrease in respiratory flux in cells exposed to both $\mathrm{C6}$ and $\mathrm{CNL}$ (Fig. 5A; ' $\triangle \mathrm{GATP}$ '). The addition of cytochrome $\mathrm{C}$ did not impact respiration, thus confirming functional integrity of the outer mitochondrial membrane across all groups (Fig. 5A; 'Cyt C'). Relative to vehicle control, respiration remained lower in C6/CNL exposed cells upon addition of glutamate, as well as succinate, following rotenone (Fig. 5A; 'Succ). Similar differences in respiration regardless of the carbon substrate strongly suggests that the respiratory impairments induced by $\mathrm{C} 6 / \mathrm{CNL}$ are most likely attributable to ETS dysregulation. Such findings are highly reminiscent to those observed in HL60/VCR and thus support a model whereby mitochondrial dysregulation, primarily localized to the ETS (e.g., Cl), may be secondary to altered SL metabolism.

Therapeutic synergy induced by co-targeting SL metabolism and respiratory $\mathrm{Cl}$ in HL-60/VCR.

Given that sweeping alterations in SL metabolism were observed alongside bioenergetic remodeling in HL-60/VCR, we sought to explore the synergistic potential of targeting respiratory complex I in conjunction with pharmacological ceramide delivery (e.g., CNL) and/or inhibition of SL metabolism. In these experiments, $\mathrm{Cl}$ was inhibited using the well characterized biguanides metformin or phenformin [35]. Induction of cellular ceramides

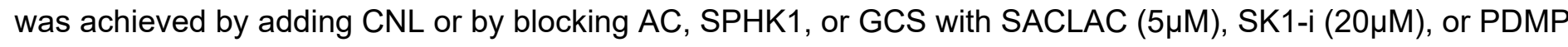
$(20 \mu \mathrm{M})$, respectively [36-41]. In HL60/VCR, 48hr exposure to CNL $(20 \mu \mathrm{M})$, nanoliposome devoid of ceramide (ghost; $20 \mu \mathrm{M})$, phenformin $(0.5 \mathrm{mM})$, or phenformin plus ghost had no impact on cell viability (Fig. 5B). Remarkably, despite no change in viability for any of the single agents, 48hr exposure to both CNL and phenformin led to a dramatic ( $>80 \%$ of control) decrease in cell viability (Fig. 5B). To furth the therapeutic efficacy of targeting mitochondrial $\mathrm{Cl}$ alongside SL metabolism, experiments were designed to determine the ability of metformin or phenformin to boost cytotoxicity of other agents that can act to increase ceramide levels (inhibitors of SL metabolism). Except for SK1-i, minimal cytotoxicity was observed in HL-60/VCR cells in the presence of the indicated doses of SACLAC, PDMP, metformin or phenformin alone (Fig. 5C-E). However, the combination of each SL enzyme inhibitor with either metformin or phenformin boosted cytotoxicity, relative to vehicle or single agent conditions (Fig. 5C-E). This relationship was particularly evident for the AC inhibitor SACLAC, where relative to the single agent conditions, the combination of SACLAC and phenformin led to a near $70 \%$ decrease in cell viability after only 24 hours (Fig. 5C). Together, these data raise the intriguing possibility that co-targeting of cellular sphingolipid metabolism and mitochondrial metabolism, specifically at $\mathrm{Cl}$, may represent a novel treatment strategy in VCR resistance. 


\section{Discussion}

A number of studies have been conducted on the relationship of SL'S and SL metabolism to chemotherapy resistance, and results have been captioned in excellent works, including reviews [21,42,43]. Gouaze-Andersson and Cabot [44] have reviewed the subject with specific regard to hematological malignancies, and recent work by Snider et al. discloses multiple actions of doxorubicin on SL metabolism in MCF-7 breast cancer cells [45], including increased levels of S1P and C16 ceramide. In agreement with recent observations in daunorubicin and cytarabine resistant AML [29], VCR resistance herein was accompanied by substantial alterations in SL composition. The novelty of the present findings stems from our focus on VCR resistance and its impact on both SL's and mitochondrial function. Moreover, given our recent findings linking SL metabolism to mitochondrial bioenergetics [7,29], we hypothesized that developing a detailed understanding of the mitochondrial perturbations that accompany the drug-resistant phenotype may reveal new opportunities for targeted therapies that regulate cancer growth. To this end, the present study leveraged a recently described mitochondrial phenotyping platform [46], specifically designed to comprehensively evaluate OXPHOS efficiency and capacity, relative to the underlying mitochondrial proteome. Using this platform, we made the exciting discovery that VCR resistance is accompanied by intrinsic mitochondrial remodeling, typified by specific limitations in respiratory $\mathrm{Cl}$. These changes were subsequently found to sensitize VCR resistant cells to combinatorial treatment directed at increasing cellular ceramides and further decreasing $\mathrm{Cl}$ flux within the mitochondria, thus offering an exciting, potential treatment strategy for combatting VCR resistance in the clinic.

With respect to SL metabolism, VCR resistance was accompanied by upregulated expression of SPHK1, $\mathrm{GCS}$, and $\mathrm{AC}$, in addition to the concomitant and expected upregulation of $\mathrm{P}$-gp, a predominant player in MDR [10]. Interestingly, the changes observed in enzyme expression were reflected in the results from lipidomic analyses. For example, increased expression of SPHK1 in HL-60/VCR cells was mirrored by elevated levels of S1P. Overexpression of AC, as noted in HL-60/VCR cells, can also contribute to elevated S1P, as AC liberates sphingosine that is converted to S1P by SPHK1. With regard to ceramide, it is possible that elevated ceramide levels in HL-60/VCR cells resulted from recycling of sphingosine via the salvage pathway of ceramide synthesis [47]. Interestingly, however, increases in cellular ceramides were countered in part by conversion to GC, a reflection of elevated levels of GCS. High GCS expression and elevated levels of GC have previously been linked to MDR [24,48-50]. As ceramides induce apoptosis, our data suggest that VCR resistant cells keep levels of ceramide "in check" via the combined activities of GCS and AC. This is supported by work of Tan et al [51] and Morad et al [52] who showed that the employ of AC and GCS inhibitors, respectively, in HL-60/VCR cells, increased ceramide levels. Interestingly, even though HL-60/VCR cells contained high levels of S1P, their growth rate was considerably lower than HL-60 cells. This biology could be related to S1P receptor status in HL-60/VCR cells, although this has not been evaluated. We also detected reductions in C18, C20, C22, and C24 molecular species of SM in HL-60/VCR cells, indicative of high sphingomyelinase activity that would contribute to increased ceramide levels. However, only some minor increases in C18, C20, C22, and C24:0 species were detected in the ceramides or in GC. This discrepancy may be a product of altered SL flux. 
With regard to P-gp, the bastion of MDR, Gouaze et al., have shown coincidental overexpression of Pgp and GCS in breast cancer and epidermoid carcinoma cells selected for resistance to natural product chemotherapy drugs [24]. Thus, the association of GCS and GC levels with drug resistance [53-55] has solid footing. Of further relevance, Shabbits and Mayer [56] have shown that ceramide sensitivity in breast cancer cells is modulated by P-gp, and using vincristine as a ceramide generator, Olshefski and Ladisch [6] have shown that GCS inhibition boosts vincristine efficacy.

In addition to changes in SL metabolism, VCR resistance in the present study was accompanied by extensive mitochondrial remodeling. In comparison to wt cells, HL-60/VCR presented with increases in basal respiration, as well as higher maximal uncoupled oxygen consumption, the latter suggestive of higher mitochondrial content. Increased reliance on mitochondrial metabolism is a commonly emerging theme in cancer drug resistance [2,3]. Although such findings are often interpreted to reflect an increased reliance on oxidative ATP synthesis, it is critical to point out that a large collection of these findings are based solely on measurements of intact cellular respirometry. As demonstrated herein, such methodologies are largely incapable of identifying nuanced bioenergetic inefficiencies across the mitochondrial network in cancer. As such, too much reliance on macro-level changes in cellular bioenergetics (i.e., binary assessments of mitochondrial versus glycolytic 'reliance') may in fact be masking a 'goldmine' of cancer-specific mitochondrial biology that if known could potentially be leveraged to develop highly efficacious targeted therapies with a favorable therapeutic index.

Results from experiments in Fig. 5 highlight the integration between SL's and mitochondrial function and suggest that this link can be exploited, therapeutically. For example, with ceramide levels already high in HL60/VCR cells compared to wild-type (see Fig. 1G), the inclusion of either SACLAC or PDMP would be expected to drive ceramide to cytotoxic levels $[29,36,57,58]$. SK1-i could also backup ceramide levels while limiting S1P's mitogenic effects. Interestingly, consequent to baseline disruptions in $\mathrm{Cl}$ expression, the addition of $\mathrm{Cl}$ inhibitors metformin or phenformin (see Fig. 4B-E) to the mix likely add "insult to injury", as amply demonstrated by the synergistic, cytotoxic outcome, most strikingly regarding the CNL-phenformin combination and the SACLAC-phenformin regimen. Moreover, it is noteworthy that we were able to mimic infringement of mitochondrial function typified in HL-60/VCR cells, by cell supplementation with either C6 or CNL.

\section{Conclusions}

In conclusion, increases in SPHK1, GCS, and AC expression that accompany VCR resistance serve to support cancer cell growth, as the coordinated action of these enzymes may limit the full cancer suppressor actions of ceramide while boosting mitogenicity and leukemic dissemination. Although levels of several ceramide molecular species increased with VCR resistance, a change perhaps favoring apoptosis, it is clear from the lipidomic profiles that VCR-resistant cells endeavor to keep ceramide levels in-check by increasing several GC and SM molecular species. Ceramides may also be of benefit in induction of autophagy for survival [59]. These factors, in conjunction with the intrinsic mitochondrial remodeling allied with VCR resistance, promote a resilient cancer phenotype, but also reveal(s) opportunities for design of novel, targeted therapeutics [21,60-62]. Our 
approach of leveraging comprehensive bioenergetic phenotyping to unveil actionable cancer-specific mitochondria targets holds great potential as a novel drug-discovery platform centered upon mitochondrial precision medicine in drug resistance that can easily be adapted across cancer types.

\section{DECLARATIONS}

Acknowledgements: Not applicable

Authors' contributions: KHFW, JTH, MK, LPK, MAMN, KLM, HSC, TEF, SFT, DJF, MK, TPL, DFC, and MCC took part in the data collection and analysis. KHFW and MCC did the study design. KHFW and MCC participated in drafting and editing the manuscript. KHFW and MCC were responsible for the funding support. All authors read and approved the final manuscript.

Funding: The work was supported by DOD-W81XWH-19-1-0213 (K.H.F.-W.) and NIH P01 CA171983 (M.C.C), as well as a grant from the Brody Brothers Foundation, Kinston, NC.

Availability of Data and Materials: The datasets generated and/or analyzed during the current study are available in the Open Science Framework (OSF) repository (DOI available on acceptance for publication). For proteomics data, all raw data are available online using accession number "JPST001142" for jPOST Repository $[63,64]$.

Ethics approval and consent to participate: Not applicable

Consent for publication: Not applicable

Competing interest: Authors declare that they have no conflicts of interest with the contents of this article. MK is Chief Medical Officer and cofounder of Keystone Nano, Inc. and TPL is a member of the scientific advisory board. TPL is on the Scientific Advisory Board and has stock options for Keystone Nano, Bioniz Therapeutics and Dren Bio. TPL and DF received honoraria from Kymera Therapeutics.

Author Details: ${ }^{1}$ Department of Biochemistry \& Molecular Biology, East Carolina University, Brody School of Medicine, and the East Carolina Diabetes and Obesity Institute, Greenville, NC 27834, USA; ${ }^{2}$ Department of Pharmacology, University of Virginia School of Medicine, Charlottesville, VA, USA; ${ }^{3}$ Department of Medicine, Hematology/Oncology, University of Virginia School of Medicine, Charlottesville, VA 22908, USA; “University of Virginia Cancer Center, Charlottesville, VA 22908, USA; ${ }^{5}$ Department of Physiology, East Carolina University, Brody School of Medicine, and the East Carolina Diabetes and Obesity Institute, Greenville, NC 27834, USA; ${ }^{6}$ Penn State Cancer Institute, Hershey, Pennsylvania.

\section{References}

1. Gottesman MM, Lavi O, Hall MD, Gillet JP. Toward a Better Understanding of the Complexity of Cancer 
Drug Resistance. Annu Rev Pharmacol Toxicol. 2016;

2. Farge T, Saland E, de Toni F, Aroua N, Hosseini M, Perry R, et al. Chemotherapy-resistant human acute myeloid leukemia cells are not enriched for leukemic stem cells but require oxidative metabolism. Cancer Discov. 2017;7:716-35.

3. Guièze R, Liu VM, Rosebrock D, Jourdain AA, Hernández-Sánchez M, Martinez Zurita A, et al. Mitochondrial Reprogramming Underlies Resistance to BCL-2 Inhibition in Lymphoid Malignancies. Cancer Cell [Internet]. Cell Press; 2019 [cited 2020 Aug 3];36:369-384.e13. Available from:

https://doi.org/10.1016/j.ccell.2019.08.005

4. Gu W, Liu T, Fan D, Zhang J, Xia Y, Meng F, et al. A6 peptide-tagged, ultra-small and reduction-sensitive polymersomal vincristine sulfate as a smart and specific treatment for CD44+ acute myeloid leukemia. $J$ Control Release. Elsevier B.V.; 2020;329:706-16.

5. Senchenkov A, Litvak DA, Cabot MC. Targeting ceramide metabolism - A strategy for overcoming drug resistance. J. Natl. Cancer Inst. 2001.

6. Olshefski RS, Ladisch S. Glucosylceramide synthase inhibition enhances vincristine-induced cytotoxicity. Int J Cancer. 2001;

7. Fisher-Wellman K, Hagen JT, Neufer PD, Kassai M, Cabot MC. On the nature of ceramide-mitochondria interactions - Dissection using comprehensive mitochondrial phenotyping. Cell Signal. 2020;

8. Morad SAF, Ryan TE, Neufer PD, Zeczycki TN, Davis TS, MacDougall MR, et al. Ceramide-tamoxifen regimen targets bioenergetic elements in acute myelogenous leukemia. J Lipid Res [Internet]. 2016;57:123142. Available from: http://www.jlr.org/lookup/doi/10.1194/jlr.M067389

9. Bartholomae S, Gruhn B, Debatin KM, Zimmermann M, Creutzig U, Reinhardt D, et al. Coexpression of Multiple ABC-Transporters is Strongly Associated with Treatment Response in Childhood Acute Myeloid Leukemia. Pediatr Blood Cancer. 2016;

10. Shaffer BC, Gillet JP, Patel C, Baer MR, Bates SE, Gottesman MM. Drug resistance: Still a daunting challenge to the successful treatment of AML. Drug Resist Updat. 2012;

11. Schmittgen TD, Livak KJ. Analyzing real-time PCR data by the comparative CT method. Nat Protoc. 2008;

12. Nolan T, Hands RE, Bustin SA. Quantification of mRNA using real-time RT-PCR. Nat Protoc. 2006;

13. McLaughlin KL, Hagen JT, Coalson HS, Nelson MAM, Kew KA, Wooten AR, et al. Novel approach to quantify mitochondrial content and intrinsic bioenergetic efficiency across organs. Sci Rep. 2020;10.

14. Fisher-Wellman KH, Davidson MT, Narowski TM, Lin C Te, Koves TR, Muoio DM. Mitochondrial Diagnostics: A Multiplexed Assay Platform for Comprehensive Assessment of Mitochondrial Energy Fluxes. 
Cell Rep. 2018;Sep 25;24:3593-606.

15. Fisher-Wellman KH, Gilliam LAA, Lin C-T, Cathey BL, Lark DS, Darrell Neufer P. Mitochondrial glutathione depletion reveals a novel role for the pyruvate dehydrogenase complex as a key $\mathrm{H}<\mathrm{inf}>2<$ inf $>0<$ inf $>2</$ inf $>$ emitting source under conditions of nutrient overload. Free Radic Biol Med. 2013;65.

16. McLaughlin KL, Kew KA, McClung JM, Fisher-Wellman KH. Subcellular proteomics combined with bioenergetic phenotyping reveals protein biomarkers of respiratory insufficiency in the setting of proofreadingdeficient mitochondrial polymerase. Sci Rep. 2020;

17. Calvo SE, Clauser KR, Mootha VK. MitoCarta2.0: An updated inventory of mammalian mitochondrial proteins. Nucleic Acids Res. 2016;

18. Naugler C, Lesack K. An open-source software program for performing Bonferroni and related corrections for multiple comparisons. J Pathol Inform. 2011;

19. Benjamini $\mathrm{Y}$, Hochberg Y. Controlling the false discovery rate: a practical and powerful approach to multiple testing. J R Stat Soc Ser B. 1995;

20. Ogretmen B, Safa AR. Identification and characterization of the MDR1 promoter-enhancing factor 1 (MEF1) in the multidrug resistant HL60/VCR human acute myeloid leukemia cell line. Biochemistry. 2000;

21. Morad SAF, Cabot MC. Ceramide-orchestrated signalling in cancer cells. Nat. Rev. Cancer. 2013.

22. Truman JP, García-Barros M, Obeid LM, Hannun YA. Evolving concepts in cancer therapy through targeting sphingolipid metabolism. Biochim. Biophys. Acta - Mol. Cell Biol. Lipids. 2014.

23. Morad SAF, Cabot MC. The Onus of Sphingolipid Enzymes in Cancer Drug Resistance. Adv Cancer Res. 2018;

24. Gouazé V, Yu JY, Bleicher RJ, Han TY, Liu YY, Wang H, et al. Overexpression of glucosylceramide synthase and $\mathrm{P}$-glycoprotein in cancer cells selected for resistance to natural product chemotherapy. Mol Cancer Ther. 2004;

25. Tan SF, Dunton W, Liu X, Fox TE, Morad SAF, Desai D, et al. Acid ceramidase promotes drug resistance in acute myeloid leukemia through NF-kB-dependent P-glycoprotein upregulation. J Lipid Res. 2019;

26. Vasan K, Werner M, Chandel NS. Mitochondrial Metabolism as a Target for Cancer Therapy. Cell Metab [Internet]. Elsevier Inc.; 2020;32:341-52. Available from: https://doi.org/10.1016/j.cmet.2020.06.019

27. Colombini M. Ceramide channels and their role in mitochondria-mediated apoptosis. Biochim. Biophys. Acta - Bioenerg. 2010.

28. Neuzil J, Dong LF, Rohlena J, Truksa J, Ralph SJ. Classification of mitocans, anti-cancer drugs acting on 
mitochondria. Mitochondrion. 2013.

29. Kao LP, Morad SAF, Davis TS, MacDougall MR, Kassai M, Abdelmageed N, et al. Chemotherapy selection pressure alters sphingolipid composition and mitochondrial bioenergetics in resistant HL-60 cells. J Lipid Res. 2019;

30. Chen J, Kao YR, Sun D, Todorova TI, Reynolds D, Narayanagari SR, et al. Myelodysplastic syndrome progression to acute myeloid leukemia at the stem cell level. Nat Med [Internet]. Springer US; 2019;25:103-10. Available from: http://dx.doi.org/10.1038/s41591-018-0267-4

31. McLaughlin KL, McClung JM, Fisher-Wellman KH. Bioenergetic consequences of compromised mitochondrial DNA repair in the mouse heart. Biochem Biophys Res Commun [Internet]. Elsevier Ltd; 2018;39. Available from: https://doi.org/10.1016/j.bbrc.2018.09.022

32. Fisher-Wellman KH, Davidson MT, Narowski TM, Lin C-T, Koves TR, Muoio DM. Mitochondrial Diagnostics: A multiplexed assay platform for comprehensive assessment of mitochondrial energy fluxes. Cell Rep [Internet]. ElsevierCompany.; 2018;In Press:3593-3606.e10. Available from:

https://doi.org/10.1016/j.celrep.2018.08.091

33. Song MS, Posse De Chaves El. Inhibition of rat sympathetic neuron apoptosis by ceramide. Role of p75NTR in ceramide generation. Neuropharmacology. 2003;45:1130-50.

34. Barth BM, Wang W, Toran PT, Fox TE, Annageldiyev C, Ondrasik RM, et al. Sphingolipid metabolism determines the therapeutic efficacy of nanoliposomal ceramide in acute myeloid leukemia. Blood Adv. 2019;3:2598-603.

35. Bridges HR, Sirviï $i^{1} / 2 \vee A$, Agip ANA, Hirst J. Molecular features of biguanides required for targeting of mitochondrial respiratory complex I and activation of AMP-kinase. BMC Biol. BMC Biology; 2016;14:1-11.

36. Pearson JM, Tan SF, Sharma A, Annageldiyev C, Fox TE, Abad JL, et al. Ceramide analogue SACLAC modulates sphingolipid levels and MCL-1 splicing to induce apoptosis in acute myeloid leukemia. Mol Cancer Res. 2020;18:352-63.

37. Kao L-P, Morad SAF, Davis TS, MacDougall MR, Kassai M, Abdelmageed N, et al. Chemotherapy selection pressure alters sphingolipid composition and mitochondrial bioenergetics in resistant HL-60 cells. J Lipid Res. 2019;60.

38. Chatzakos V, Rundlöf AK, Ahmed D, De Verdier PJ, Flygare J. Inhibition of sphingosine kinase 1 enhances cytotoxicity, ceramide levels and ROS formation in liver cancer cells treated with selenite. Biochem Pharmacol. 2012;84:712-21.

39. Maurer BJ, Melton L, Billups C, Cabot MC, Reynolds CP. Synergistic cytotoxicity in solid tumor cell lines between $\mathrm{N}$-(4-hydroxyphenyl)retinamide and modulators of ceramide metabolism. J Natl Cancer Inst. 
2000;92:1897-909.

40. Yang YL, Ji C, Cheng L, He L, Lu CC, Wang R, et al. Sphingosine kinase-1 inhibition sensitizes curcumininduced growth inhibition and apoptosis in ovarian cancer cells. Cancer Sci. 2012;103:1538-45.

41. Huang W, Tsai C, Chen C, Chen T, Chen Y, Lin Y, et al. Glucosylceramide synthase inhibitor PDMP sensitizes chronic myeloid leukemia T315I mutant to Bcr-Abl inhibitor and cooperatively induces glycogen synthase kinase-3-regulated apoptosis. FASEB J. 2011;25:3661-73.

42. Giussani P, Tringali C, Riboni L, Viani P, Venerando B. Sphingolipids: Key regulators of apoptosis and pivotal players in cancer drug resistance. Int. J. Mol. Sci. 2014.

43. Lee WK, Kolesnick RN. Sphingolipid abnormalities in cancer multidrug resistance: Chicken or egg? Cell. Signal. 2017.

44. Gouaze-Andersson V, C. Cabot M. Sphingolipid Metabolism and Drug Resistance in Hematological Malignancies. Anticancer Agents Med Chem. 2012;

45. Snider JM, Trayssac M, Clarke CJ, Schwartz N, Snider AJ, Obeid LM, et al. Multiple actions of doxorubicin on the sphingolipid network revealed by flux analysis. J Lipid Res. 2019;

46. McLaughlin KL, Hagen JT, Coalson HS, Nelson MAM, Kew KA, Wooten AR, et al. Novel approach to quantify mitochondrial content and intrinsic bioenergetic efficiency across organs. Sci Rep. 2020;

47. Kitatani K, Idkowiak-Baldys J, Hannun YA. The sphingolipid salvage pathway in ceramide metabolism and signaling. Cell. Signal. 2008.

48. Gouazé-Andersson V, Yu JY, Kreitenberg AJ, Bielawska A, Giuliano AE, Cabot MC. Ceramide and glucosylceramide upregulate expression of the multidrug resistance gene MDR1 in cancer cells. Biochim Biophys Acta - Mol Cell Biol Lipids. 2007;

49. Messner MC, Cabot MC. Glucosylceramide in humans. Adv Exp Med Biol. 2010;

50. Liu YY, Patwardhan GA, Xie P, Gu X, Giuliano AE, Cabot MC. Glucosylceramide synthase, a factor in modulating drug resistance, is overexpressed in metastatic breast carcinoma. Int J Oncol. 2011;

51. Tan SF, Liu X, Fox TE, Barth BM, Sharma A, Turner SD, et al. Acid ceramidase is upregulated in AML and represents a novel therapeutic target. Oncotarget. 2016;

52. Morad S a F, Tan S-F, Feith DJ, Kester M, Claxton DF, Loughran TP, et al. Modification of sphingolipid metabolism by tamoxifen and $\mathrm{N}$-desmethyltamoxifen in acute myelogenous leukemia-Impact on enzyme activity and response to cytotoxics. Biochim Biophys Acta. 2015;

53. Lavie Y, Cao HT, Bursten SL, Giuliano AE, Cabot MC. Accumulation of glucosylceramides in multidrug- 
resistant cancer cells. J Biol Chem. 1996;

54. Lucci A, Cho WI, Han TY, Giuliano AE, Morton DL, Cabot MC. Glucosylceramide: A marker for multipledrug resistant cancers. Anticancer Res. 1998;

55. LIU Y, HAN T, GIULIANO AE, CABOT MC. Ceramide glycosylation potentiates cellular multidrug resistance. FASEB J. 2001;

56. Shabbits JA, Mayer LD. P-glycoprotein modulates ceramide-mediated sensitivity of human breast cancer cells to tubulin-binding anticancer drugs. Mol Cancer Ther. 2002;

57. Baran Y, Bielawski J, Gunduz U, Ogretmen B. Targeting glucosylceramide synthase sensitizes imatinibresistant chronic myeloid leukemia cells via endogenous ceramide accumulation. J Cancer Res Clin Oncol. 2011;137:1535-44.

58. Yamane M, Miyazawa K, Moriya S, Abe A, Yamane S. D,L-Threo-1-phenyl-2-decanoylamino-3morpholino-1-propanol (DL-PDMP) increases endoplasmic reticulum stress, autophagy and apoptosis accompanying ceramide accumulation via ceramide synthase 5 protein expression in A549 cells. Biochimie [Internet]. Elsevier Masson SAS; 2011;93:1446-59. Available from:

http://dx.doi.org/10.1016/j.biochi.2011.04.016

59. Jiang W, Ogretmen B. Autophagy paradox and ceramide. Biochim. Biophys. Acta - Mol. Cell Biol. Lipids. Elsevier; 2014. p. 783-92.

60. Bonhoure E, Pchejetski D, Aouali N, Morjani H, Levade T, Kohama T, et al. Overcoming MDR-associated chemoresistance in HL-60 acute myeloid leukemia cells by targeting shingosine kinase-1. Leukemia. 2006;

61. Paugh SW, Paugh BS, Rahmani M, Kapitonov D, Almenara JA, Kordula T, et al. A selective sphingosine kinase 1 inhibitor integrates multiple molecular therapeutic targets in human leukemia. Blood. 2008;

62. Ogretmen B. Sphingolipid metabolism in cancer signalling and therapy. Nat. Rev. Cancer. 2017.

63. Okuda S, Watanabe Y, Moriya Y, Kawano S, Yamamoto T, Matsumoto M, et al. JPOSTrepo: An international standard data repository for proteomes. Nucleic Acids Res. 2017;

64. Deutsch EW, Csordas A, Sun Z, Jarnuczak A, Perez-Riverol Y, Ternent T, et al. The ProteomeXchange consortium in 2017: Supporting the cultural change in proteomics public data deposition. Nucleic Acids Res. 2017;

\section{Figure Legends}


Fig. 1. Alterations in SL metabolism underlie VCR resistance in HL-60 cells. (A) VCR cytotoxicity. HL-60 and HL-60/VCR cells were seeded in 96-well plates (50,000 cells/well) and exposed to VCR concentrations indicated for $48 \mathrm{hr}$. Viability was determined by PI staining. (B) Cell growth rates determined by viable cell counts. VCR was present in HL-60/VCR growth medium. (C) ABC transporter gene expression profile. Changes in gene expression in HL-60/VCR cells are represented as fold-increase over levels measured in wt cells. (D) Representative immunoblots for SPHK1, GCS, AC, P-gp, and $\beta$-actin. (E) Immunoblot quantification represented by fold-increases in blot density over wt. (F) Long-chain bases and S1P profiles. (G) Ceramide, GC, and SM molecular species profiled in wt and HL-60/VCR cells. Figures generated using GraphPad Prism 8 software (Version 8.4.2). Data are Mean \pm SEM, (A-B) N=6/group, (C-F) N=3/group, (G) N=4-7/group. * $P<0.05,{ }^{* *} P<0.01$, ${ }^{* * *} \mathrm{P}<0.001,{ }^{* * * *} \mathrm{P}<0.0001$.

Fig. 2. Increased basal and maximal respiration accompanies VCR resistance. (A) Oxygen consumption in intact HL-60 wt and HL-60/VCR cells under basal conditions, as well as following the addition of oligomycin (Oligo), FCCP (max rate depicted based on titrations of $0.5,1,2$, and $3 \mu \mathrm{M}$ ), rotenone (Rot), and antimycin $\mathrm{A}$ (Ant). (B) FCCP stimulated respiration corrected for oxygen consumption remaining following rotenone/antimycin. (C) Percent decrease in basal respiration induced by oligomycin in wt cells, as well as vehicle or verapamil $(10 \mu \mathrm{M})$ treated HL-60/VCR cells. (D) Oxygen consumption in digitonin $(0.02 \mathrm{mg} / \mathrm{mL})$ permeabilized cells in the absence of substrates (Digi), as well as following the addition of saturating substrate (Multi; pyruvate/malate/glutamate/octanoyl-I-carnitine/succinate), FCCP titration, cytochrome C (Cyt), and Rot/Ant. All experiments were conducted in VCR-free medium. Figures generated using GraphPad Prism 8 software (Version 8.4.2). Data are Mean \pm SEM, (A, B, D) $N=4-10 /$ group, (C) N=3-5/group. * $P<0.05,{ }^{* *} P<0.01$, ${ }^{* * *} \mathrm{P}<0.001,{ }^{* * * *} \mathrm{P}<0.0001$.

Fig. 3. Comprehensive mitochondrial phenotyping reveals specific $\mathrm{Cl}$ deficiency in HL-60/VCR. All experiments were performed in isolated mitochondria. (A) Relationship between $\mathrm{JO}_{2}$ and ATP free energy $\left(\triangle G_{A T P}\right)$ clamped with the CK clamp in mitochondria energized with Multi. (B) Respiratory conductance - slope of the relationship between $\mathrm{JO}_{2}$ and $\Delta \mathrm{G}_{\text {ATP. }}$ (C) Relationship between $N A D(P) H / N A D(P)^{+}$redox and ATP free energy $\left(\triangle G_{A T P}\right)$ clamped with the CK clamp in mitochondria energized with Multi. (D-F) Relationship between $J_{2}$ and ATP free energy $\left(\Delta G_{A T P}\right)$ clamped with the CK clamp in mitochondria energized with Pyr/M, Succ/R, and G/M. (G) Respiration experiments in mitochondria exposed to saturating ADP, followed by the addition of $\mathrm{DHO}$, and teriflunomide. Bar graph inset displays $\mathrm{DHO}$-specific flux calculated from comparing respiration in the presence of $\mathrm{DHO}$ minus that observed in the presence of teriflunomide. $(\mathbf{H})$ Representative trace of a mitochondrial $\mathrm{H}_{2} \mathrm{O}_{2}$ emission experiment in wt and $\mathrm{HL}-60$ /VCR mitochondria. Data depicts fluorescence in response to mitochondrial addition, as well as Pyr/M. (I) Quantified mitochondrial $\mathrm{H}_{2} \mathrm{O}_{2}$ emission. (A-I) Data normalized to protein corrected for each sample's mitochondrial enrichment factor (MEF), assessed via nLCMS/MS (see methods). Figures generated using GraphPad Prism 8 software (Version 8.4.2). Data are Mean \pm SEM, (A-C) N=3-11/group, (D-E) N=9-10/group, (F) N=4/group, (G) N=7-8/group, (I) $N=5 / g r o u p . ~ * P<0.05$, ${ }^{* *} \mathrm{P}<0.01,{ }^{* * *} \mathrm{P}<0.001,{ }^{* * *} \mathrm{P}<0.0001$. 
Fig. 4 Decreased Cl expression underlies VCR resistance. (A) Label-free nLC-MS/MS was performed on mitochondrial lysates from each sample. Volcano plot depicting changes in the mitochondrial proteome between HL-60/VCR and wt. Protein subunits of each respiratory complex (CI, CII, CIII, CIV) are indicated by color. (B) Cartoon depicting $\mathrm{Cl}$ inhibition by rotenone. (C) Cell viability in response to 24 hours of exposure to increasing concentrations of rotenone in wt and HL-60/VCR cells. Viability assessed via counting in the presence of trypan blue. Figures generated using GraphPad Prism 8 software (Version 8.4.2) and Biorender. Data are Mean \pm SEM, (A) $\mathrm{N}=5$ /group, (C) N=6/group. ${ }^{*} \mathrm{P}<0.05,{ }^{* *} \mathrm{P}<0.01,{ }^{* *} \mathrm{P}<0.001,{ }^{* * * *} \mathrm{P}<0.0001$.

Fig. 5. Mitochondrial $\mathrm{Cl}$ inhibition combined with various ceramide analogues results in synergistic cytotoxicity. (A) Respiration in permeabilized HL-60 wt cells following exposure to vehicle C6 (10 $\mathrm{MM})$ or CNL $(10 \mu \mathrm{M})$ for 7 -days. Cells were permeabilized with digitonin $(0.02 \mathrm{mg} / \mathrm{mL})$ and respiration was assessed in response to the indicated additions. Data normalized to viable cell count. (B-E) All experiments were done in HL-60/VCR cells. (B) Cell viability, determined by viable cell count, in HL-60/VCR cells exposed for 48hr to CNL $(20 \mu \mathrm{M})$, ghost $(20 \mu \mathrm{M})$, phenformin $(0.5 \mathrm{mM}), \mathrm{CNL}(20 \mu \mathrm{M})+$ phenformin $(0.5 \mathrm{mM})$, or ghost $(20 \mu \mathrm{M})+$ phenformin

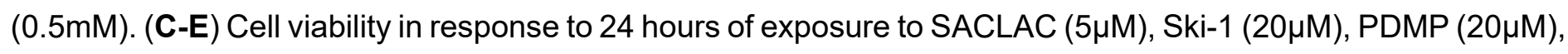
metformin $(5 \mathrm{mM})$ or phenformin $(0.5 \mathrm{mM})$. Metformin and phenformin were administered alone or in combination with SACLAC, Ski-1, or PDMP. Viability assessed via counting in the presence of trypan blue. Figures generated using GraphPad Prism 8 software (Version 8.4.2). Data are Mean \pm SEM, (A, C-E) N=3/group, (B) N=6-9/group. ${ }^{*} \mathrm{P}<0.05,{ }^{* *} \mathrm{P}<0.01,{ }^{* * *} \mathrm{P}<0.001,{ }^{* * * *} \mathrm{P}<0.0001$.

\section{SUPPLEMENTAL TABLES}

Supplement Table 1 - (A) Exported results from PDv2.2 (Proteome ID: UP000005640). (B) Analyzed master protein expression and calculation of sample-specific MEF (data were searched against the Uniprot Homo Sapiens reference proteome). (C) Exported results from PDv2.2 (MitoCarta 2.0 Database). (D) Analyzed mitochondrial master protein expression. 
A

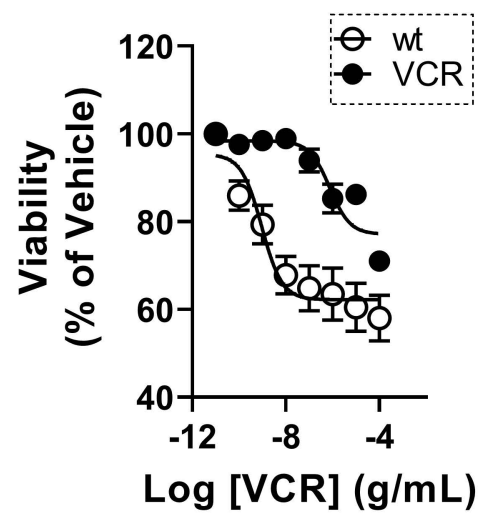

C

D

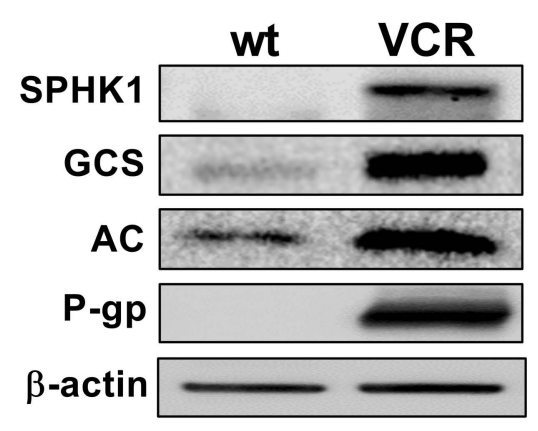

G

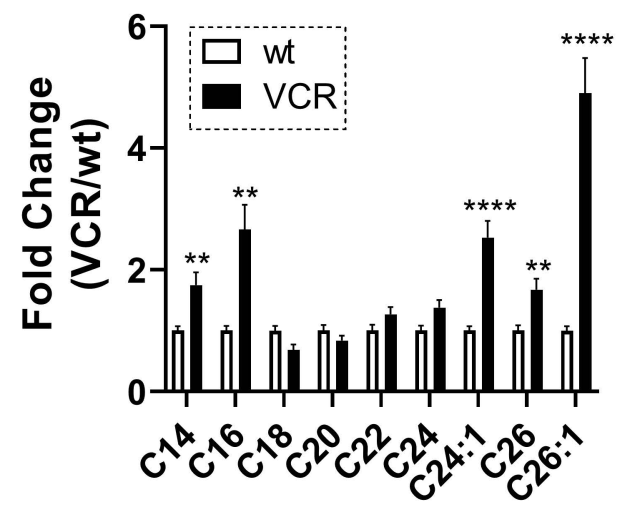

Ceramides

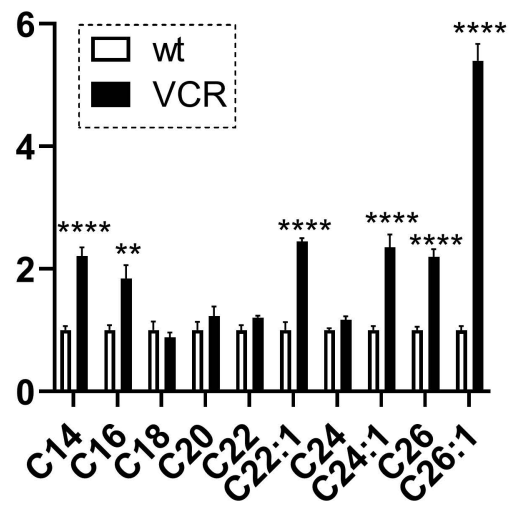

GC
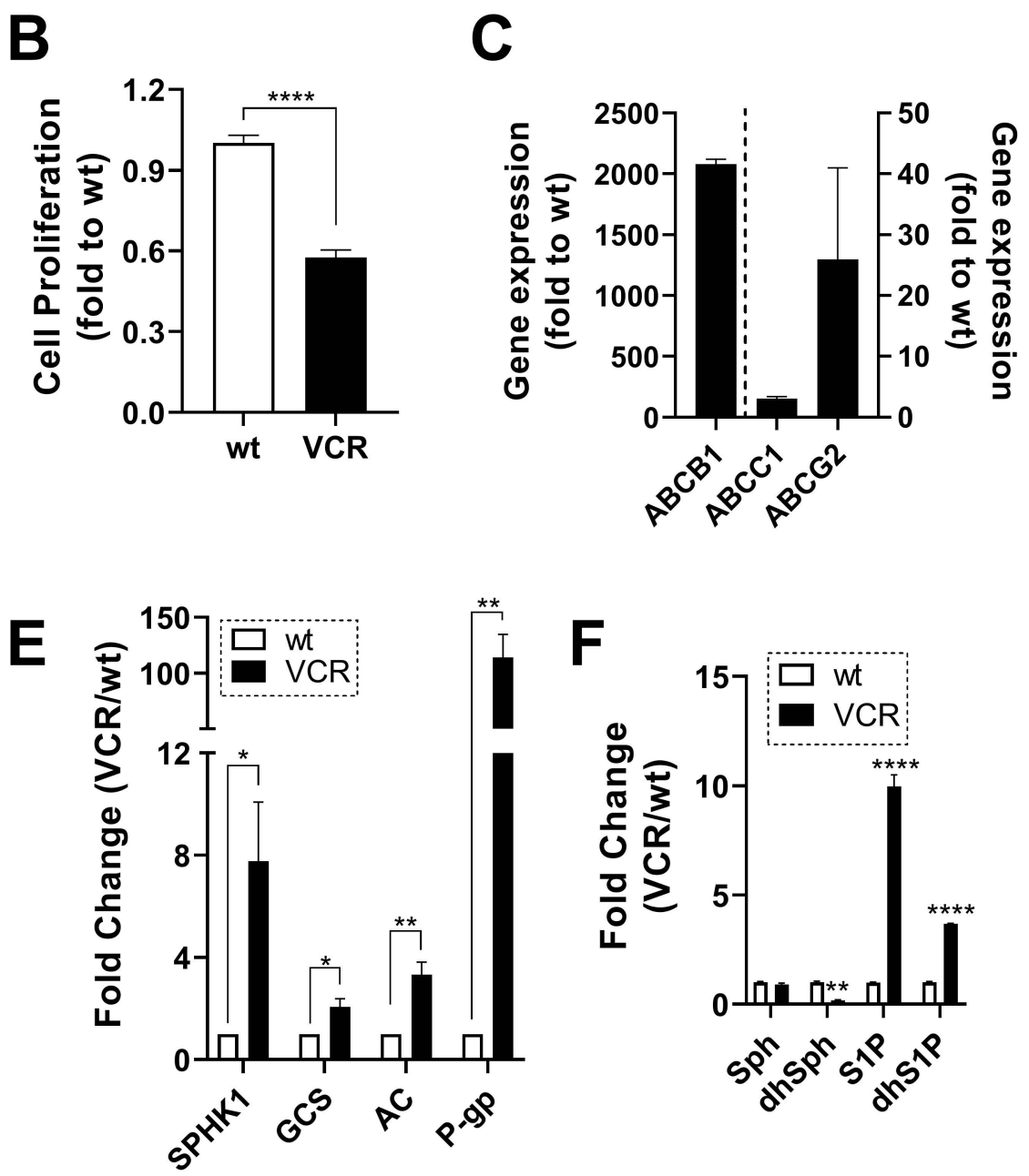

SM

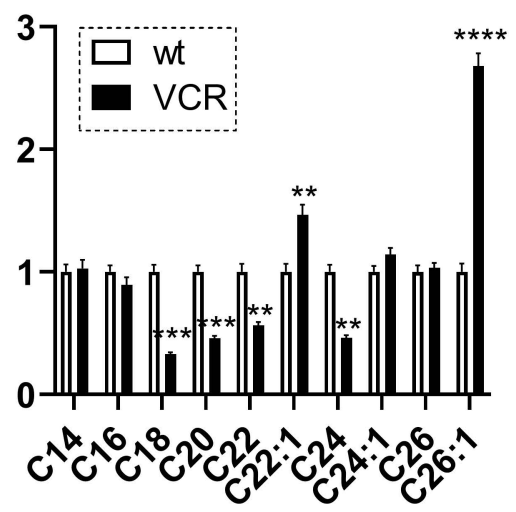




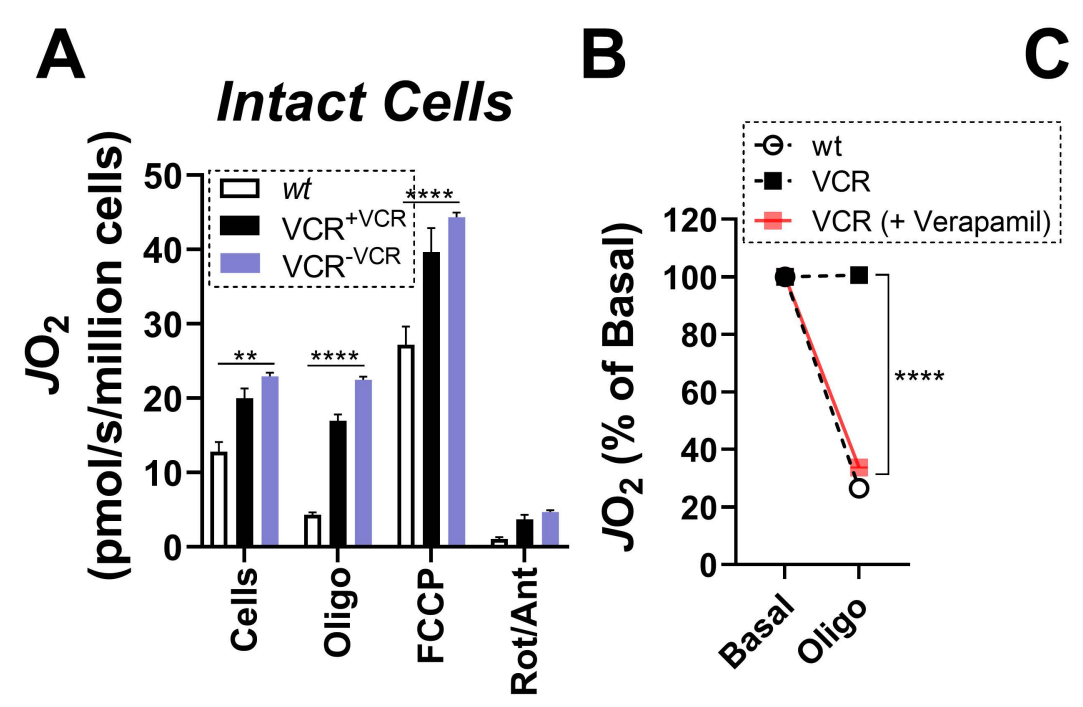

D

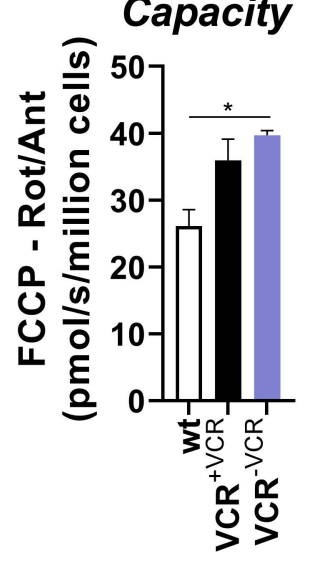

Permeabilized Cells

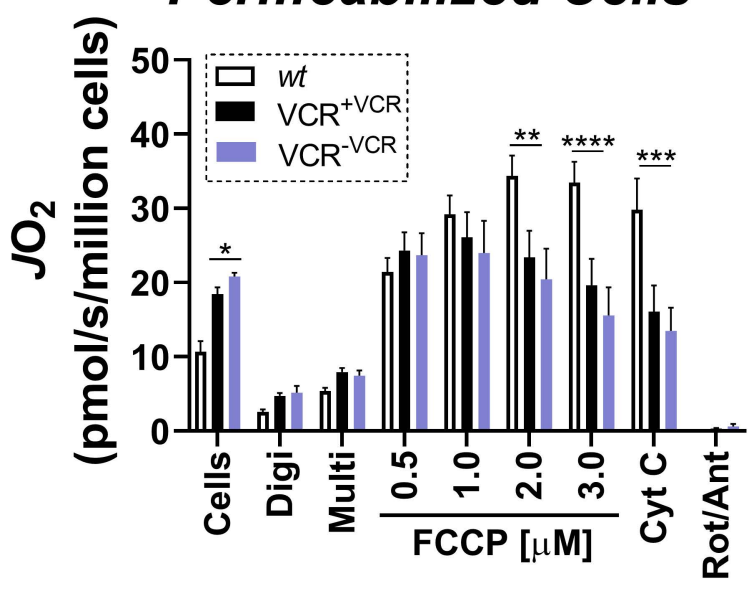



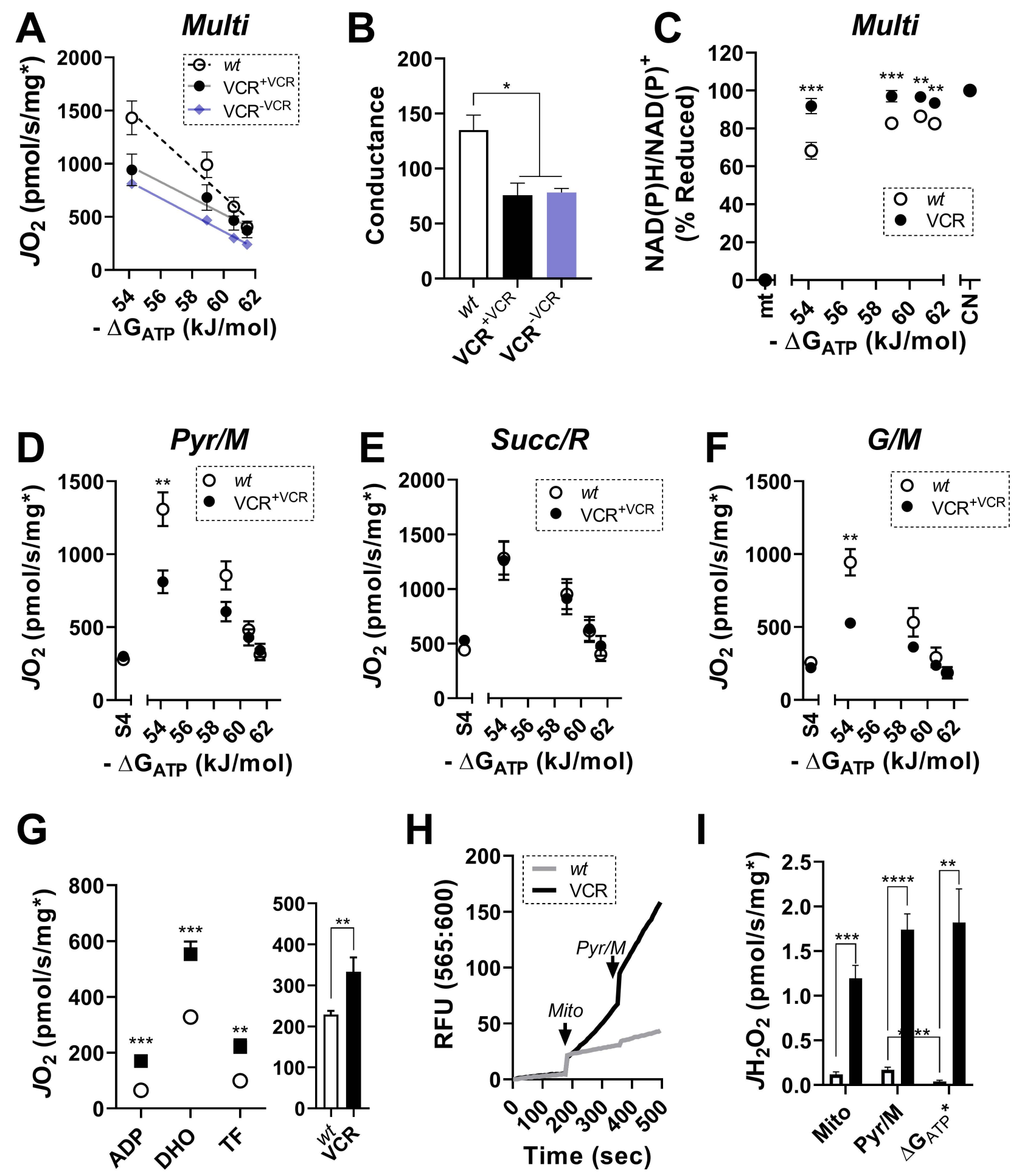


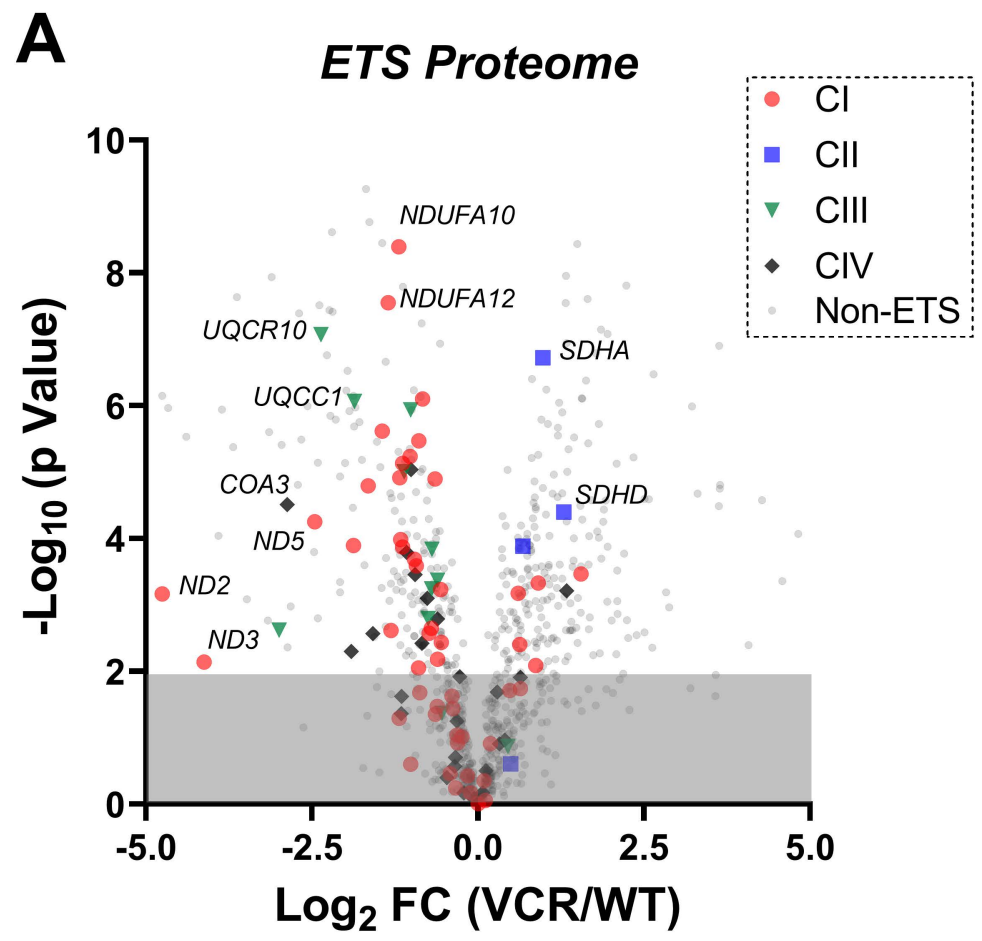

B
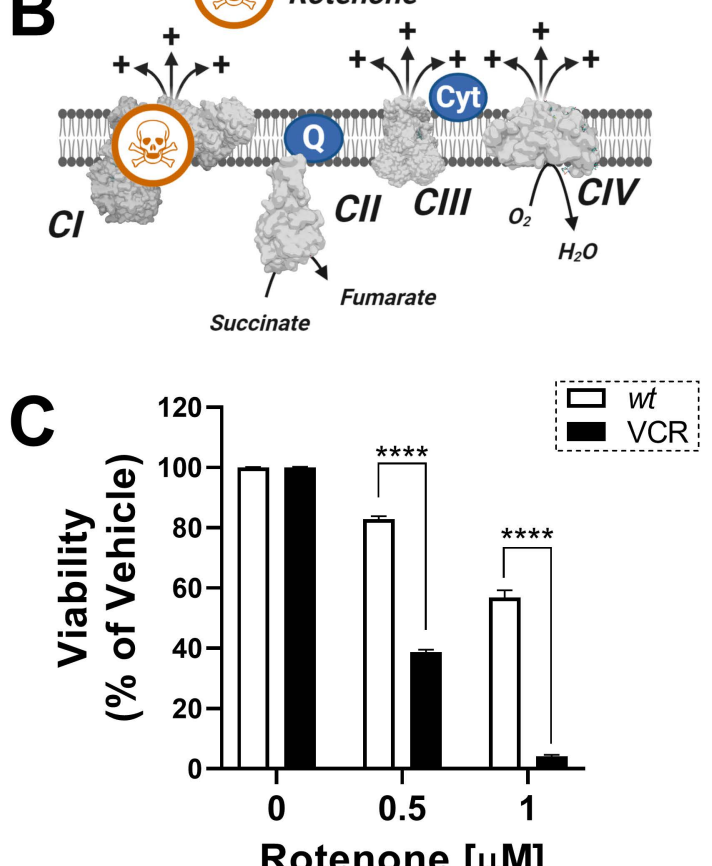
A
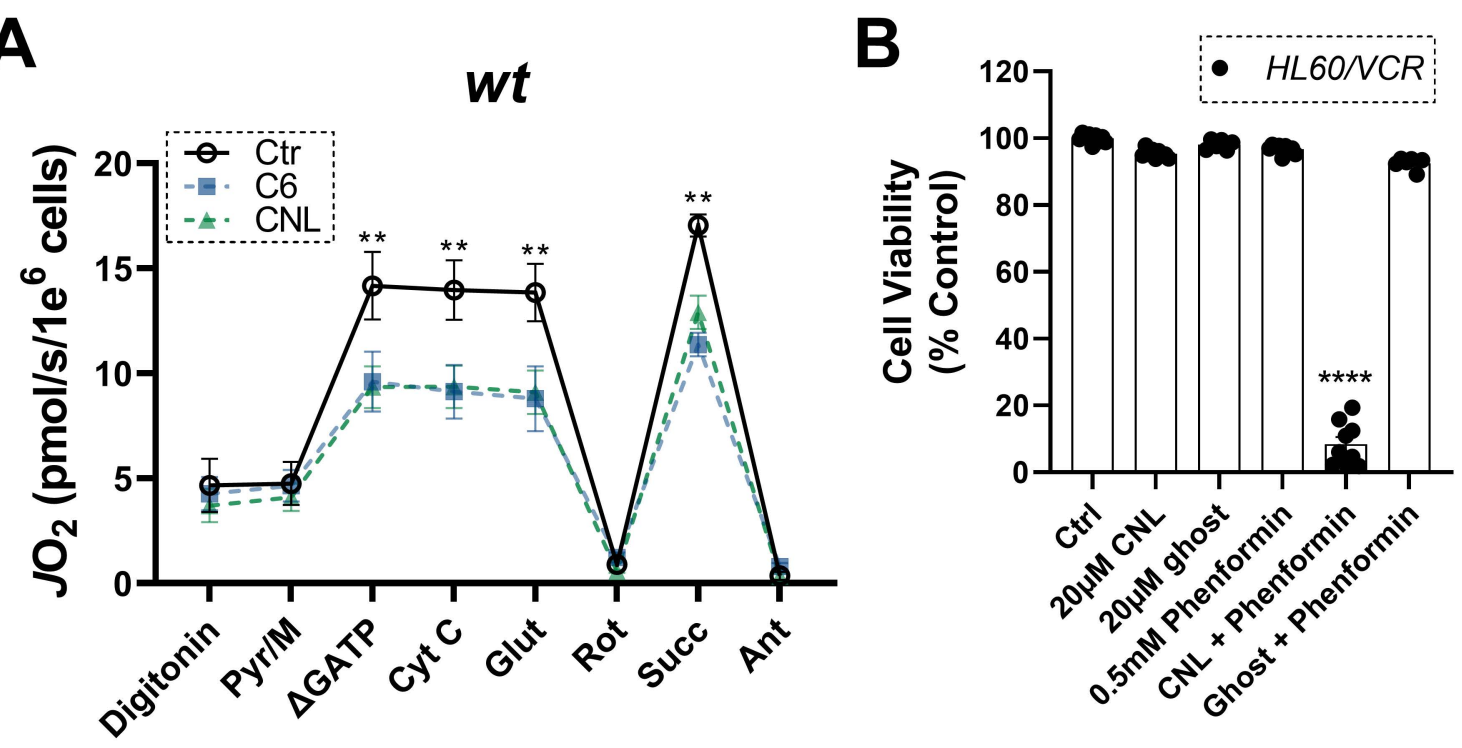

C

SACLAC

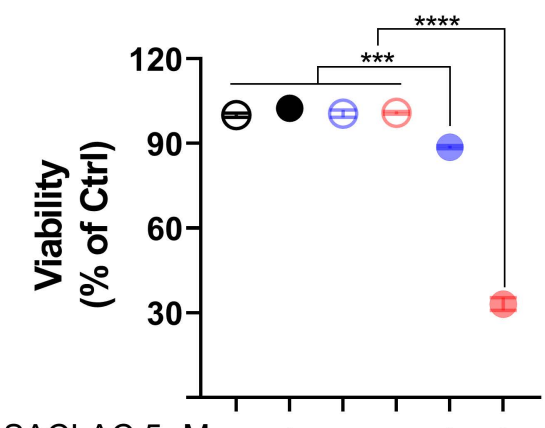

SACLAC $5 \mu \mathrm{M}-+--++$ Metformin $5 \mathrm{mM}--+-+$ Phenformin 0.5mM --+-+

\section{D}

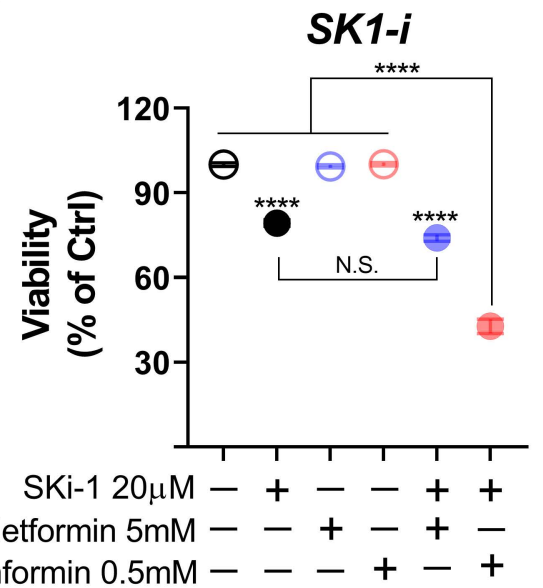

$\mathbf{E}$

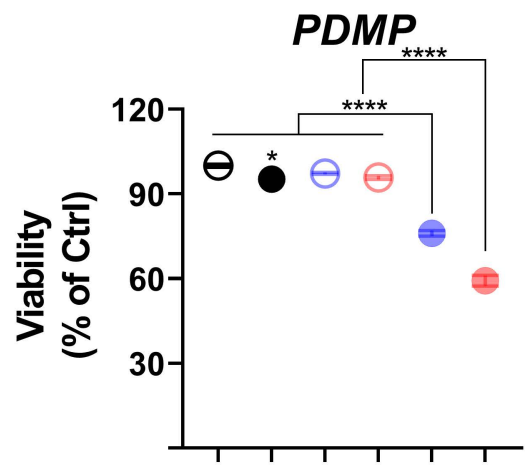

PDMP $20 \mu \mathrm{M}-+--++$

Metformin $5 \mathrm{mM}--+-+$

Phenformin $0.5 \mathrm{mM}--+++$ 
Figures
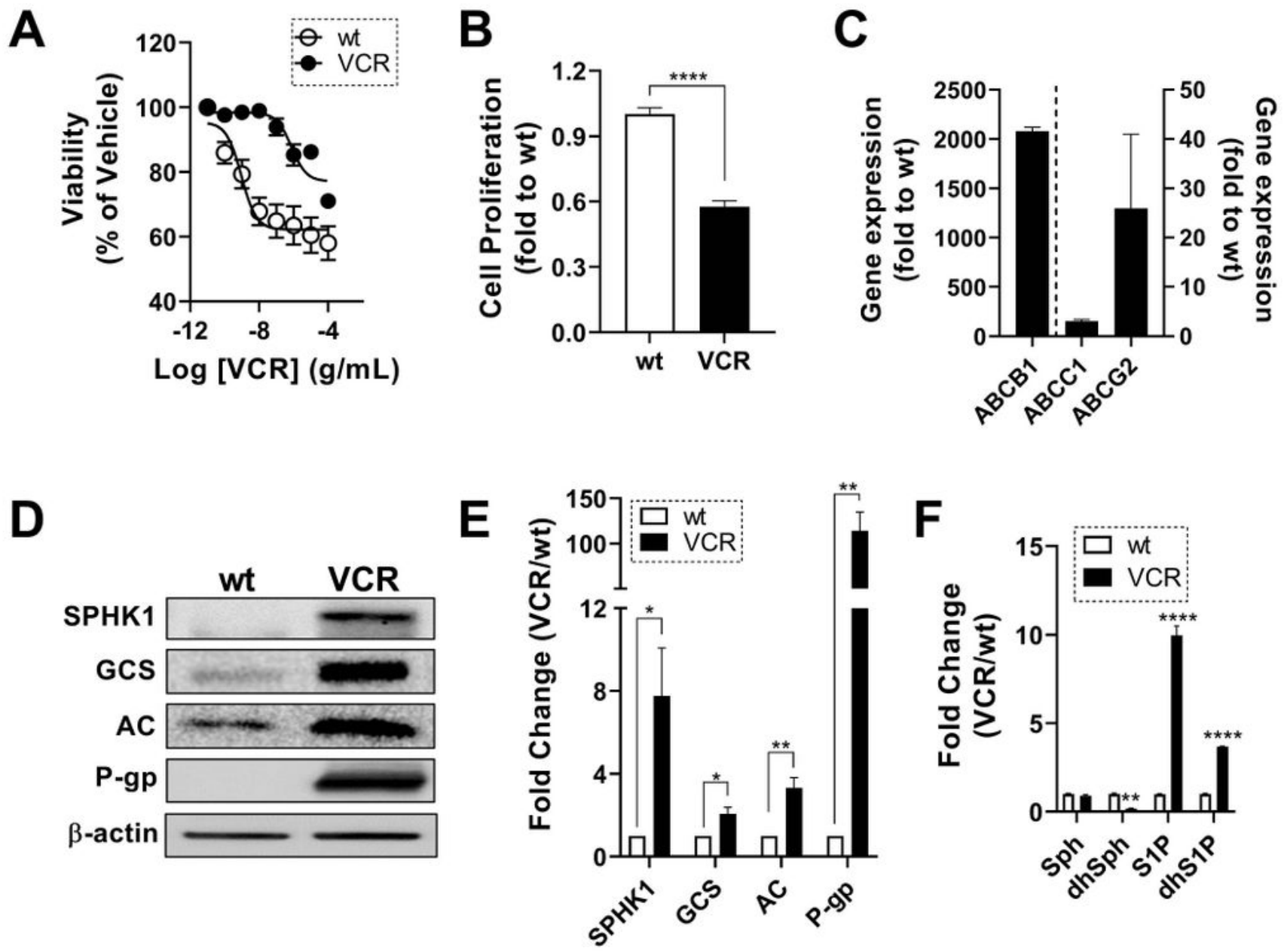

G

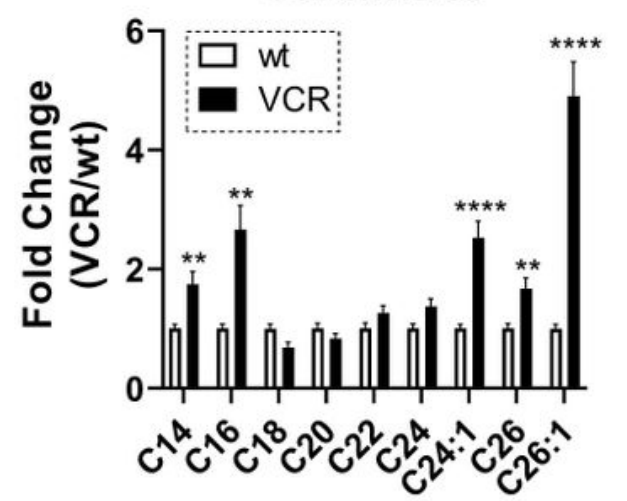

Ceramides

GC
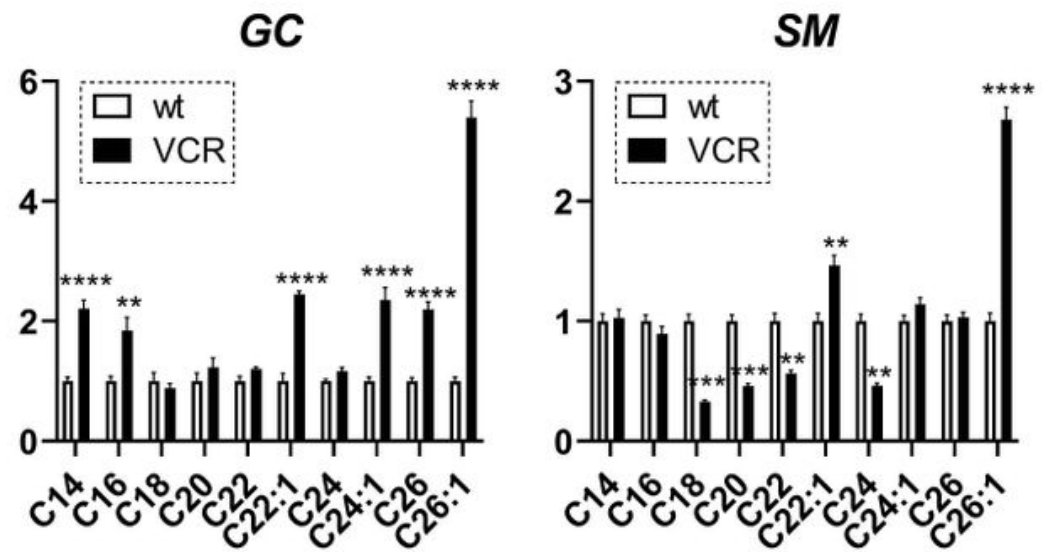

Figure 1

Alterations in SL metabolism underlie VCR resistance in HL-60 cells. (A) VCR cytotoxicity. HL-60 and HL$60 / \mathrm{VCR}$ cells were seeded in 96-well plates (50,000 cells/well) and exposed to VCR concentrations indicated for $48 \mathrm{hr}$. Viability was determined by PI staining. (B) Cell growth rates determined by viable cell 
counts. VCR was present in HL-60/VCR growth medium. (C) ABC transporter gene expression profile. Changes in gene expression in HL-60/VCR cells are represented as fold-increase over levels measured in wt cells. (D) Representative immunoblots for SPHK1, GCS, AC, P-gp, and $\beta$-actin. (E) Immunoblot quantification represented by fold-increases in blot density over wt. (F) Long-chain bases and S1P profiles. (G) Ceramide, GC, and SM molecular species profiled in wt and HL-60/VCR cells. Figures generated using GraphPad Prism 8 software (Version 8.4.2). Data are Mean $\pm S E M$, (A-B) N=6/group, (CF) $\mathrm{N}=3$ /group, $(\mathrm{G}) \mathrm{N}=4-7 /$ group. ${ }^{*} \mathrm{P}<0.05,{ }^{*} \mathrm{P}<0.01, * * * \mathrm{P}<0.001,{ }^{*} * * \mathrm{P}<0.0001$
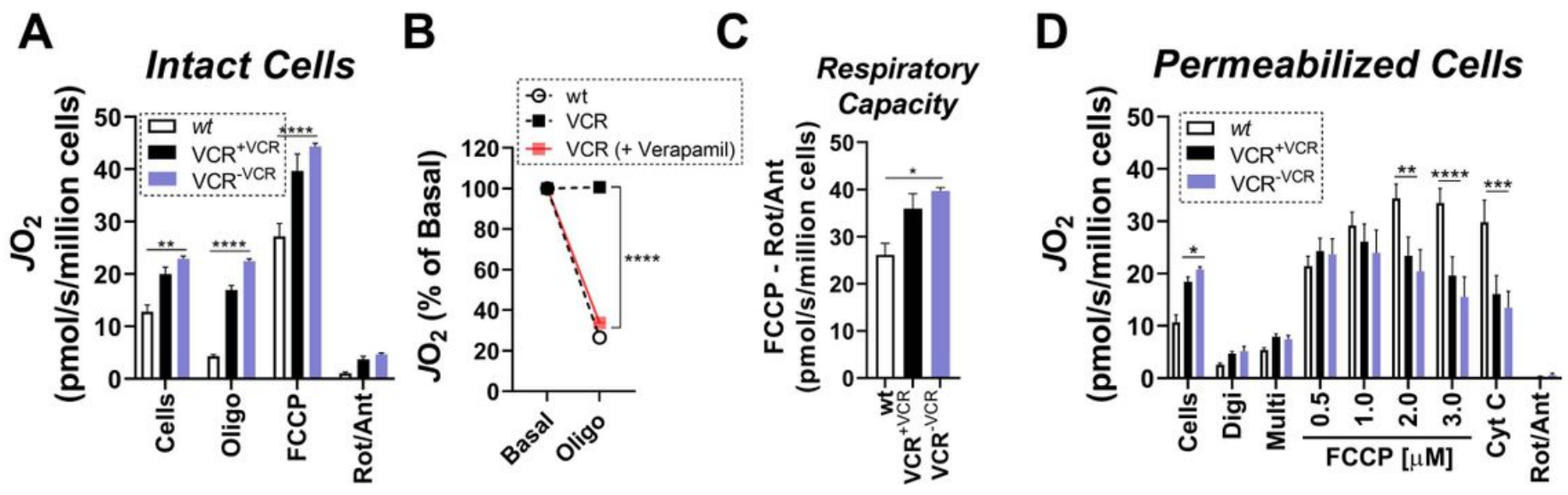

\section{Figure 2}

Increased basal and maximal respiration accompanies VCR resistance. (A) Oxygen consumption in intact HL-60 wt and HL-60/VCR cells under basal conditions, as well as following the addition of oligomycin (Oligo), FCCP (max rate depicted based on titrations of $0.5,1,2$, and $3 \mu \mathrm{M}$ ), rotenone (Rot), and antimycin A (Ant). (B) FCCP stimulated respiration corrected for oxygen consumption remaining following rotenone/antimycin. (C) Percent decrease in basal respiration induced by oligomycin in wt cells, as well as vehicle or verapamil $(10 \mu \mathrm{M})$ treated HL-60/VCR cells. (D) Oxygen consumption in digitonin $(0.02 \mathrm{mg} / \mathrm{mL})$ permeabilized cells in the absence of substrates (Digi), as well as following the addition of saturating substrate (Multi; pyruvate/malate/glutamate/octanoyl-I-carnitine/succinate), FCCP titration, cytochrome C (Cyt), and Rot/Ant. All experiments were conducted in VCR-free medium. Figures generated using GraphPad Prism 8 software (Version 8.4.2). Data are Mean \pm SEM, (A, B, D) N=4-10/group, (C) N=35/group. ${ }^{*} P<0.05, * * P<0.01, * \star * P<0.001, * \star \star * P<0.0001$. 

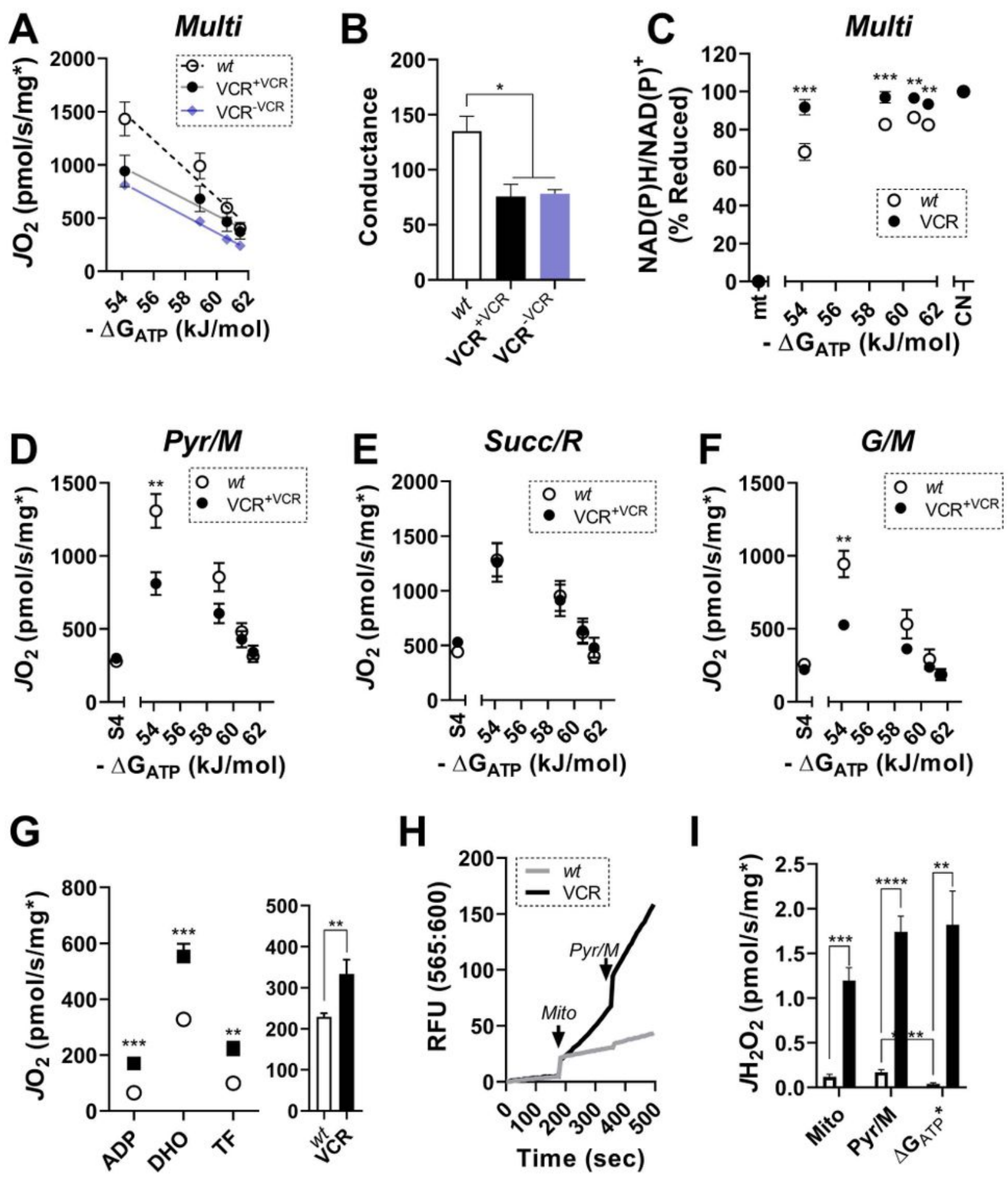

Figure 3

Comprehensive mitochondrial phenotyping reveals specific $\mathrm{Cl}$ deficiency in HL-60/VCR. All experiments were performed in isolated mitochondria. (A) Relationship between JO2 and ATP free energy ( $\triangle$ GATP) clamped with the CK clamp in mitochondria energized with Multi. (B) Respiratory conductance - slope of the relationship between JO2 and $\triangle$ GATP. (C) Relationship between NAD(P)H/NAD(P)+ redox and ATP free energy $(\triangle \mathrm{GATP})$ clamped with the CK clamp in mitochondria energized with Multi. (D-F) Relationship 
between J02 and ATP free energy ( $\triangle \mathrm{GATP}$ ) clamped with the CK clamp in mitochondria energized with Pyr/M, Succ/R, and G/M. (G) Respiration experiments in mitochondria exposed to saturating ADP, followed by the addition of DHO, and teriflunomide. Bar graph inset displays DHO-specific flux calculated from comparing respiration in the presence of $\mathrm{DHO}$ minus that observed in the presence of teriflunomide.

(H) Representative trace of a mitochondrial H2O2 emission experiment in wt and HL-60/VCR mitochondria. Data depicts fluorescence in response to mitochondrial addition, as well as Pyr/M. (I) Quantified mitochondrial H2O2 emission. (A-I) Data normalized to protein corrected for each sample's mitochondrial enrichment factor (MEF), assessed via nLC $\triangle M S / M S$ (see methods). Figures generated using GraphPad Prism 8 software (Version 8.4.2). Data are Mean \pm SEM, (A-C) N=3-11/group, (D-E) N=910/group, (F) N=4/group, (G) N=7-8/group, (I) N=5/group. ${ }^{*} P<0.05$, ${ }^{\star \star} P<0.01,{ }^{\star \star *} P<0.001, * \star \star \star P<0.0001$
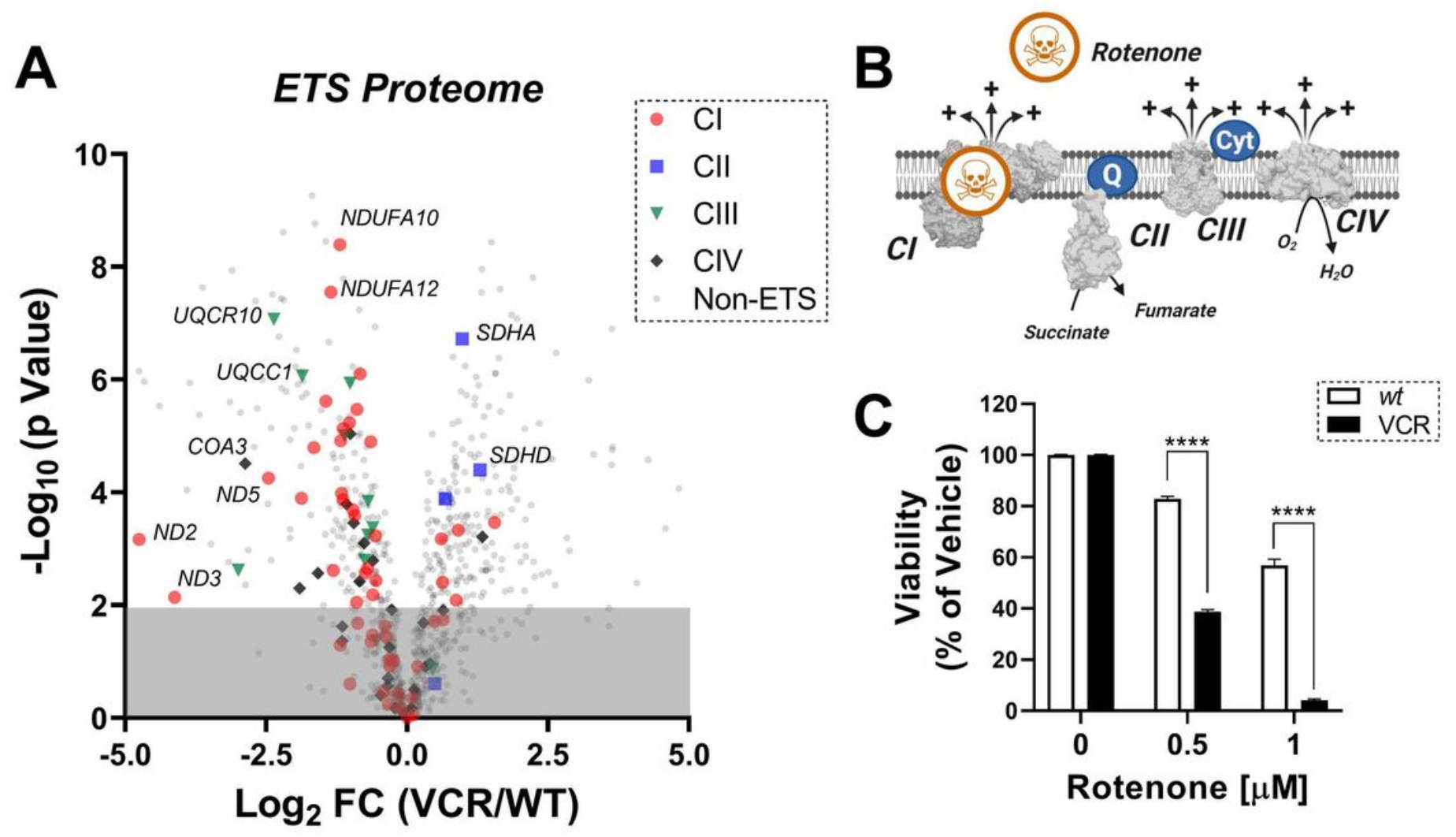

Figure 4

Decreased Cl expression underlies VCR resistance. (A) Label-free nLC-MS/MS was performed on mitochondrial lysates from each sample. Volcano plot depicting changes in the mitochondrial proteome between HL-60/VCR and wt. Protein subunits of each respiratory complex (Cl, CII, CIII, CIV) are indicated by color. (B) Cartoon depicting $\mathrm{Cl}$ inhibition by rotenone. (C) Cell viability in response to 24 hours of exposure to increasing concentrations of rotenone in wt and HL-60/VCR cells. Viability assessed via counting in the presence of trypan blue. Figures generated using GraphPad Prism 8 software (Version 8.4.2) and Biorender. Data are Mean $\pm S E M,(A) N=5$ /group, (C) $N=6 /$ group. ${ }^{*} P<0.05, * * P<0.01$, ${ }^{* \star *} \mathrm{P}<0.001, * \star \star \star P<0.0001$. 
A

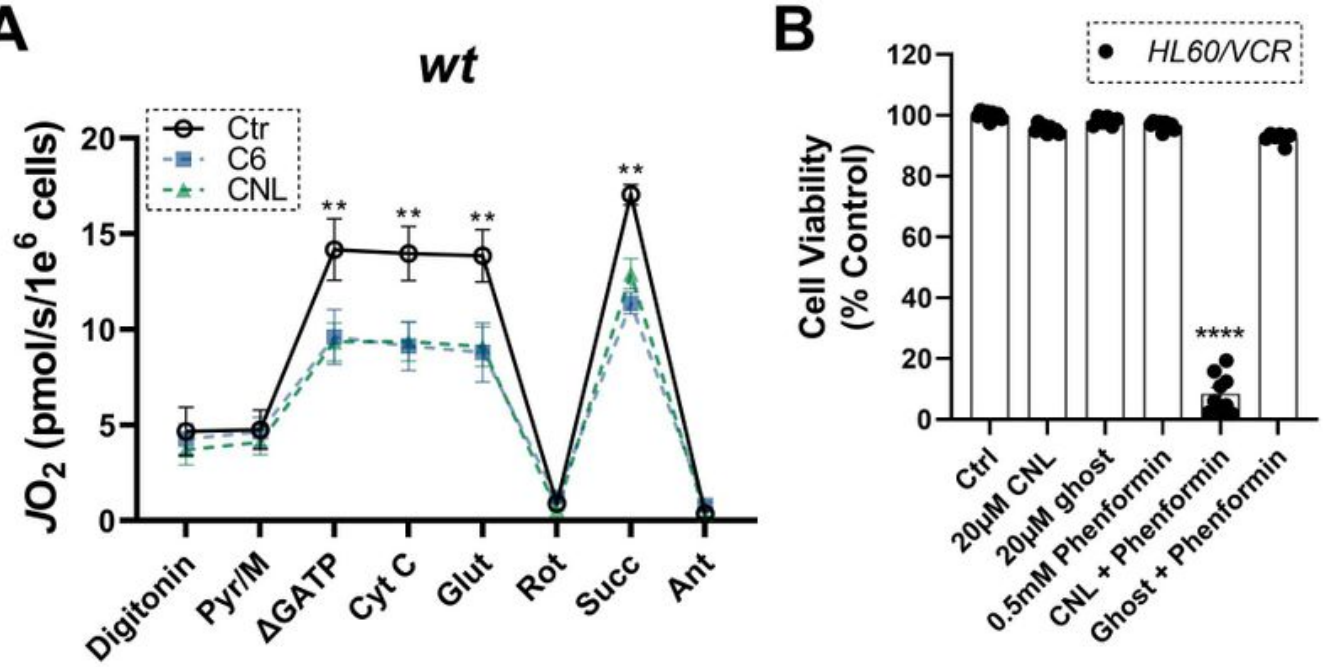

C

SACLAC

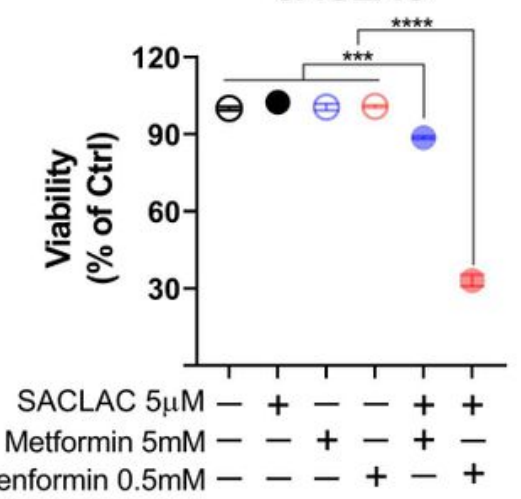

D

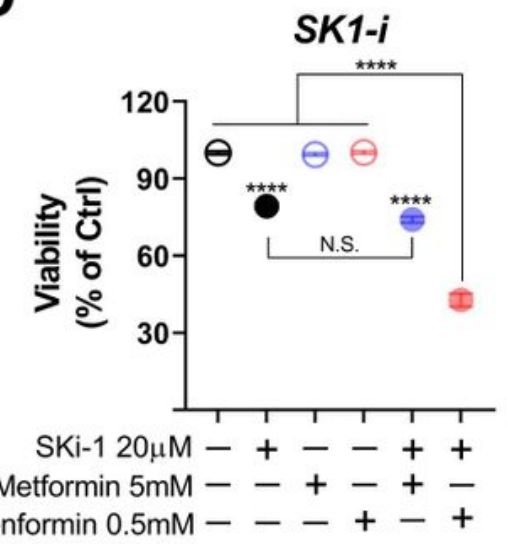

$\mathbf{E}$

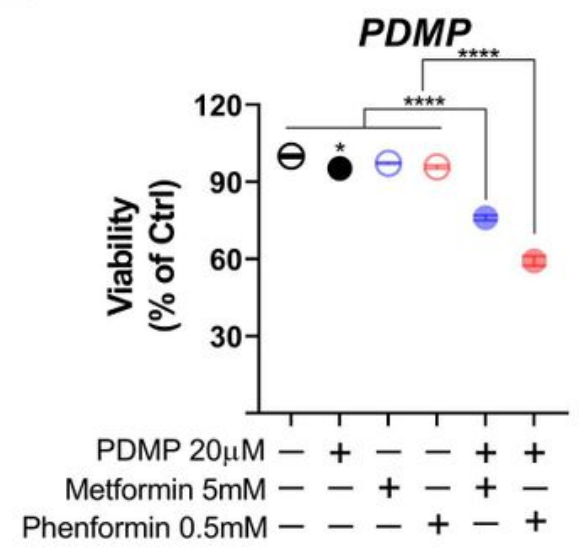

Figure 5

Mitochondrial $\mathrm{Cl}$ inhibition combined with various ceramide analogues results in synergistic cytotoxicity. (A) Respiration in permeabilized HL-60 wt cells following exposure to vehicle C6 $(10 \mu \mathrm{M})$ or CNL $(10 \mu \mathrm{M})$ for 7-days. Cells were permeabilized with digitonin $(0.02 \mathrm{mg} / \mathrm{mL})$ and respiration was assessed in response to the indicated additions. Data normalized to viable cell count. (B-E) All experiments were done in HL-60/VCR cells. (B) Cell viability, determined by viable cell count, in HL-60/VCR cells exposed for 48hr 
to $\mathrm{CNL}(20 \mu \mathrm{M})$, ghost $(20 \mu \mathrm{M})$, phenformin $(0.5 \mathrm{mM}), \mathrm{CNL}(20 \mu \mathrm{M})+$ phenformin $(0.5 \mathrm{mM})$, or ghost $(20 \mu \mathrm{M})$ + phenformin $(0.5 \mathrm{mM})$. (C-E) Cell viability in response to 24 hours of exposure to SACLAC $(5 \mu \mathrm{M})$, Ski-1 $(20 \mu \mathrm{M})$, PDMP $(20 \mu \mathrm{M})$, metformin $(5 \mathrm{mM})$ or phenformin $(0.5 \mathrm{mM})$. Metformin and phenformin were administered alone or in combination with SACLAC, Ski-1, or PDMP. Viability assessed via counting in the presence of trypan blue. Figures generated using GraphPad Prism 8 software (Version 8.4.2). Data are Mean $\pm S E M,(A, C-E) N=3 /$ group, (B) $N=6-9 /$ group. ${ }^{*} P<0.05$, ${ }^{*} P<0.01, * \star * P<0.001, * \star \star * P<0.0001$.

\section{Supplementary Files}

This is a list of supplementary files associated with this preprint. Click to download.

- SupplementaryTable1.xlsx 